\title{
Identification of Natural Product Sulfuretin-Derivatives as Inhibitors for the Endoplasmic Reticulum Redox Protein ERO1a
}

\author{
Brennan Johnson ${ }^{1}$, Sridhar Reddy Kaulagari ${ }^{4}$, Wei-Chih Chen ${ }^{1}$, Karen Hayes ${ }^{4}$, Werner J. \\ Geldenhuys $^{2,3}$, Lori Hazlehurst ${ }^{1,2,4^{*}}$ \\ ${ }^{1}$ Cancer Center, West Virginia University, Morgantown WV 26501 \\ ${ }^{2}$ Department of Pharmaceutical Sciences, School of Pharmacy West Virginia University, \\ Morgantown WV 26505 \\ ${ }^{3}$ Department of Neuroscience, School of Medicine, West Virginia University, Morgantown, WV \\ 26501 \\ ${ }^{4}$ Modulation Therapeutics Inc, Morgantown WV 26506
}

*Corresponding Author: 1 Medical Center Drive, Morgantown, WV 26506; Email:

lahazlehurst@hsc.wvu.edu;

\section{Contents}

$\begin{array}{ll}\text { Chemistry: Materials and instruments } & \text { S2 }\end{array}$

$\begin{array}{ll}\text { Synthesis of ERO1 } \alpha \text { inhibitors } & \text { S2 }\end{array}$

Scheme 1. Synthesis of aurones (114-127) and chalcones (128-131) S3

$\begin{array}{ll}\text { General method of synthesis } & \text { S3 }\end{array}$

Analysis of compounds $\quad$ S4

$\begin{array}{ll}\text { References } & \text { S9 }\end{array}$

${ }^{1} \mathrm{H},{ }^{13} \mathrm{C}$ and ${ }^{13} \mathrm{C}$-DEPT \& ${ }^{19} \mathrm{~F}$ NMR Spectra with HPLC traces of compounds $\quad$ S10

$\begin{array}{ll}\text { Supplemental Figure 1 } & \text { S55 }\end{array}$

$\begin{array}{ll}\text { Supplemental Figure 2 } & \text { S56 }\end{array}$

$\begin{array}{ll}\text { Supplemental Table } 1 & \text { S57 }\end{array}$ 


\section{Experimental Procedures}

\section{Chemistry. Materials \& Instruments}

All reagents and solvents were obtained in highest grade possible from commercial sources and used as received, unless otherwise specified. Purification of the compounds from the reactions was performed by trituration or either by flash chromatography or HPLC. Reactions were monitored for progress by thin layer chromatography (TLC) on pre-coated glass plates (Merck KGaA Silica gel $60 \mathrm{~F}_{254}$ ). Flash chromatography was performed using silica gel (60 A, 60-200 $\mu \mathrm{m}$, Acros Organics). HPLC purification was performed on Agilent 1100 series preparatory system using

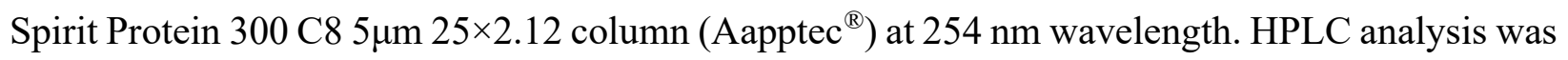
performed on Agilent 1100 Series instrument using HyperClone $5 \mu$ C8 (MOS) $1150 \times 2.00 \mathrm{~mm}$ $5 \mu$ micron column (Phenomenex ${ }^{\circledR}$ ) at $254 \mathrm{~nm}$ wavelength. ${ }^{1} \mathrm{H}$ NMR, ${ }^{13} \mathrm{C}$ NMR and ${ }^{19} \mathrm{~F}$ NMR spectra were recorded on a JEOL $400 \mathrm{MHz}$ spectrometer. ${ }^{1} \mathrm{H}$ spectra were recorded at $400 \mathrm{MHz}$ and ${ }^{13} \mathrm{C}$ NMR spectra were recorded using a proton-decoupled pulse sequence run at $100 \mathrm{MHz}$.

${ }^{19} \mathrm{~F}$ spectra were recorded at $376 \mathrm{MHz}$. Chemical shifts $(\delta)$ are expressed in parts per million (ppm) and the shifts were corrected as $\delta 7.26$ for $\mathrm{CDCl}_{3}, \delta 2.54$ for DMSO- $\mathrm{d}_{6}$ and for proton. Chemical shifts were corrected as $\delta 77.36$ for $\mathrm{CDCl}_{3}, \delta 40.45$ for DMSO-d 6 for carbon NMRs. Signal splitting patters were described as singlet (s), doublet (d), triplet (t), quartet (q), double doublet (dd) or a multiplet $(\mathrm{m})$. Coupling constants $(J)$ were quoted to the nearest $0.1 \mathrm{~Hz}$. Due to trans/cis isomerization of some unhindered molecules; more signals were observed in ${ }^{1} \mathrm{H}$ and ${ }^{13} \mathrm{C}$ spectra than would be expected for the pure trans product. High resolution mass measurements were carried out on Thermo Fisher Q Exactive Orbitrap mass spectrometer. Melting points were measured on Thermo Scientific MEL-TEMP (Model 1101D) instrument coupled with FLUKE 51 II digital thermometer and were uncorrected.

\section{Synthesis of ERO1a Inhibitors.}

6-Hydroxy-2-benzylidene-1-benzofuran-3-one derivatives were synthesized following previously reported methods. Initially, compounds 114-127 were synthesized by Claisen-Schmidt condensation between 6-hydroxy-3-coumaronone and substituted benzaldehydes in good yields in the presence of aqueous sodium hydroxide. ${ }^{1,2}$ Compounds $128-131$ were synthesized using similar conditions from acetophenones as shown in Scheme 1. ${ }^{3,4}$ Introduction of the hydrophilic and 
hydrophobic, electron withdrawing and electron donating substitutions at ortho-, meta-, and parapositions allowed to investigate their effects on the biological activity.

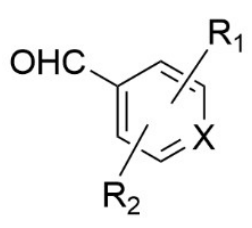

$\mathrm{R}_{2}$

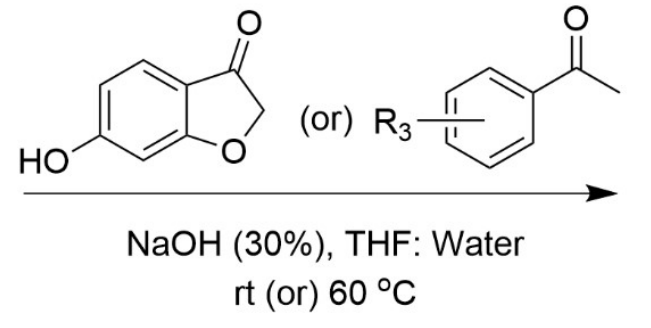

$$
\begin{aligned}
& \mathrm{R}_{1}=\mathrm{H}, \mathrm{Ph}, \mathrm{CF}_{3}, \mathrm{COOH}, \\
& \mathrm{R}_{2}=\mathrm{H}, \mathrm{F}, \mathrm{Cl}, \mathrm{NMe}_{2} \\
& \mathrm{R}_{3}=\mathrm{Cl}, \mathrm{Br}, \mathrm{CF}_{3} \\
& \mathrm{X}=\mathrm{N} \text { or } \mathrm{CH}
\end{aligned}
$$

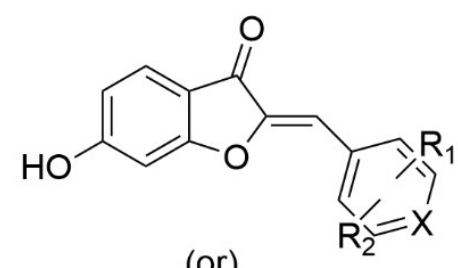

(or)

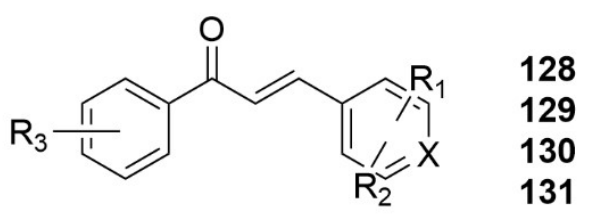

Scheme 1. Schematic diagram for the synthesis of aurones (114-127) and chalcones (128-131)

\section{General Method of Synthesis}

To a mixture of 6-Hydroxy-3-coumaronone or substituted acetophenone, $(1.4 \mathrm{mmol})$ in tetrahydrofuran and water (10 mL, typically 1:1 ratio), an equivalent amount of aryl aldehydes was added and stirred at room temperature. $30 \%$ sodium hydroxide $(500 \mu \mathrm{L})$ was added dropwise to the above solution and the resulting reaction was heated to gentle reflux for 2-6 hours. Upon the completion of the reaction by thin layer chromatography, reaction mixture was neutralized by the dropwise addition of acetic acid. Solvents were removed under reduced pressure and the resulting crude was extracted into ethyl acetate $(100 \mathrm{~mL})$ with saturated brine washings $(2 \times 25 \mathrm{~mL})$. The organic layer was dried over anhydrous sodium sulfate and concentrated to afford the crude product that was purified by trituration in ether. The product from the resulting supernatant and from reaction where precipitation did not form was subjected to either flash chromatography $(10 \%$ ethyl acetate, $90 \%$ hexanes) or reverse phase HPLC to obtain (recover) final compounds as solids (yellow to orange red). 


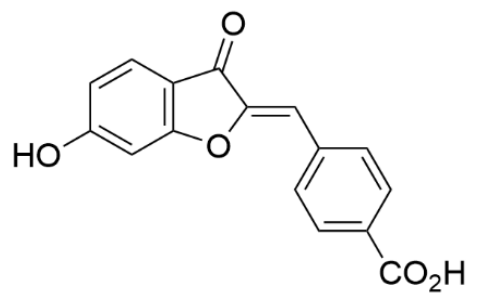

Benzoic acid, 4-[(6-hydroxy-3-oxo-2(3H)-benzofuranylidene)methyl]- (2Z)- (SR-F-114)

${ }^{1} \mathrm{H}$ NMR (400 MHz, DMSO-d $) \delta 11.36-11.33(\mathrm{~s}, 1 \mathrm{H}), 8.12-8.04$ (q, $\left.J_{1}=14, J_{2}=8.4,4 \mathrm{H}\right), 7.72-$ $7.67(\mathrm{~d}, J=8.4,1 \mathrm{H}), 6.90-6.88(\mathrm{~s}, 1 \mathrm{H}), 6.87-8.85(\mathrm{~d}, J=2.4,1 \mathrm{H}), 6.80-6.72\left(\mathrm{dd}, J_{2}=2.4, J_{1}=8.8\right.$, 1H); ${ }^{13} \mathrm{C}$ NMR (100 MHz, DMSO-d $) \delta 182.35,169.07,167.78,167.75,149.24,137.24,131.92$, $131.88,130.65,127.13,114.21,113.45,109.8,99.68 ;{ }^{13} \mathrm{C}$ DEPT NMR (100 MHz, DMSO-d 6$) \delta$ 131.63, 130.40, 126.89, 113.96, 109.55, 99.43; HRMS (ESI-TOF) m/z [M-H] negative calc'd. for $\mathrm{C}_{16} \mathrm{H}_{9} \mathrm{O}_{5} 281.0455$, found 281.0456 ., yield 63\%, yellow solid. Melting Point $=317-326.5^{\circ} \mathrm{C}$

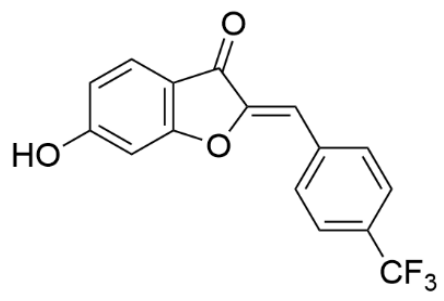

3(2H)-Benzofuranone, 6-hydroxy-2-[[4-(trifluoromethyl)phenyl]methylene]-, (2Z)- (SR-F115)

${ }^{1} \mathrm{H}$ NMR (400 MHz, DMSO-d 6 ) $\delta 11.41-11.31$ (s, 1H), 8.22-8.15 (d, $\left.J=8.0,2 \mathrm{H}\right), 7.92-7.85$ (d, $J$ $=8.0,2 \mathrm{H}), 7.72-7.67(\mathrm{~d}, J=8.4,1 \mathrm{H}), 6.94-6.90(\mathrm{~s}, 1 \mathrm{H}), 6.86-6.84(\mathrm{~d}, J=2.0,1 \mathrm{H}), 6.80-6.76(\mathrm{dd}$, $\left.J_{2}=2.4, J_{1}=8.8,1 \mathrm{H}\right) ;{ }^{13} \mathrm{C}$ NMR $(100 \mathrm{MHz}$, DMSO-d 6 ) $\delta 184.20,170.46,168.96,150.46,137.62$, $132.54,127.30,126.72,126.68,114.47,114.23,110.19,99.68 ;{ }^{13} \mathrm{C}$ DEPT NMR (100 MHz, DMSO-d $\left._{6}\right) \delta 132.09,126.95,126.42,114.02,108.94,99.40 ;$ HRMS (ESI-TOF) m/z [M-H] negative calc'd. for $\mathrm{C}_{16} \mathrm{H}_{8} \mathrm{~F}_{3} \mathrm{O}_{3} 305.0431$, found 305.0432 . 76\% yield, light yellow solid. Melting Point $=241.9^{\circ} \mathrm{C}$ 


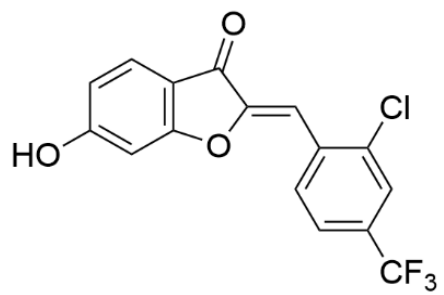

3(2H)-Benzofuranone, 6-hydroxy-2-[[2-chloro-4-(trifluoromethyl)phenyl]methylene]-, (2Z)(SR-F-119)

${ }^{1} \mathrm{H}$ NMR $(100 \mathrm{MHz}$, DMSO-d 6$) \delta 8.53-8.47(\mathrm{~s}, 1 \mathrm{H}), 7.85-7.79(\mathrm{~d}, J=8.0,1 \mathrm{H}), 7.74-7.68\left(\mathrm{dd}, J_{I}\right.$ $\left.=8.4, J_{2}=2.0,1 \mathrm{H}\right), 7.26-7.20(\mathrm{~d}, J=8.8,1 \mathrm{H}), 6.64-6.60(\mathrm{~s}, 1 \mathrm{H}), 6.06-6.00\left(\mathrm{dd}, J_{2}=1.6, J_{1}=8.8\right.$, $1 \mathrm{H}), 5.83(\mathrm{~d}, J=1.2,1 \mathrm{H}) ;{ }^{13} \mathrm{C}$ NMR $\left(100 \mathrm{MHz}, \mathrm{DMSO}-\mathrm{d}_{6}\right) \delta 182.47,175.91,170.49,154.07$, $133.29,131.82,129.31,128.99,127.65,127.61,126.33,126.30,125.92,103.96,99.62,97.92 ;{ }^{13} \mathrm{C}$ DEPT NMR (100 MHz, DMSO-d 6 ) $\delta 131.89,127.64,126.33,125.91,121.09,99.61,97.92$; HRMS (ESI-TOF) $\mathrm{m} / \mathrm{z}[\mathrm{M}-\mathrm{H}]$ negative calc'd. for $\mathrm{C}_{16} \mathrm{H}_{7} \mathrm{ClF}_{3} \mathrm{O}_{3} 339.0041$, found 339.0041. 85\% yield, orange solid. Melting Point $=310.5^{\circ} \mathrm{C}$

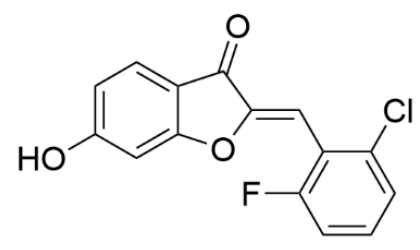

(2Z)-2-(2-chloro-6-fluorobenzylidene)-6-hydroxy-1-benzofuran-3(2H)-one (SR-F-125)

${ }^{1} \mathrm{H}$ NMR (100 MHz, DMSO-d 6$) \delta$ 11.43-11.35 (s, 1H), 7.73-7.67 (d, $\left.J=8.0,1 \mathrm{H}\right), 7.62-7.48(\mathrm{~m}$, $2 \mathrm{H}), 7.46-7.38(\mathrm{t}, J=8.4,1 \mathrm{H}), 6.80-6.68(\mathrm{~m}, 3 \mathrm{H}) ;{ }^{13} \mathrm{C}$ NMR (100 MHz, DMSO-d 6$) \delta 182.33$, $168.86,167.54,148.41,141.98,140.12,132.63,132.18,130.00,128.96,128.08,127.68,126.93$, 114.05, 113.75, 110.98, 99.61; ${ }^{13} \mathrm{C}$ DEPT NMR (100 MHz, DMSO-d 6 ) $\delta 132.39,127.17,126.30$, 115.81, 113.99, 101.28, 99.25; HRMS (ESI-TOF) m/z [M-H] negative calc'd. for $\mathrm{C}_{15} \mathrm{H}_{7} \mathrm{ClFO}_{3}$ 289.0073, found 289.0077. 89\% yield, yellow solid. Melting Point $=277.6^{\circ} \mathrm{C}$ 


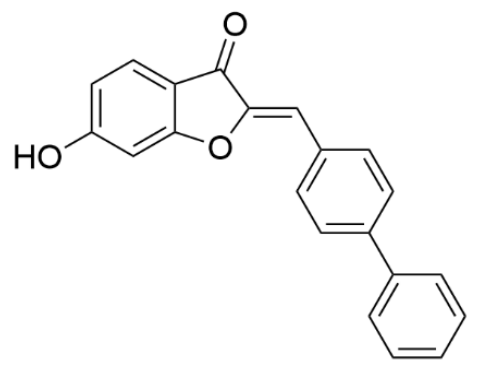

(2Z)-2-(1,1'-biphenyl-4-ylmethylene)-6-hydroxy-1-benzofuran-3(2H)-one (SR-F-126)

${ }^{1} \mathrm{H}$ NMR (400 MHz, DMSO-d 6 ) $\delta$ 11.31-11.26 (s, 1H), 8.12-8.06 (d, $\left.J=8.0,2 \mathrm{H}\right), 7.88-7.83(\mathrm{~d}, J$ $=8.4,2 \mathrm{H}), 7.82-7.76(\mathrm{~d}, J=7.6,2 \mathrm{H}), 7.71-7.66(\mathrm{~d}, J=8.4,1 \mathrm{H}), 7.58-7.50(\mathrm{t}, J=7.6,2 \mathrm{H}), 7.48-$ $7.41(\mathrm{t}, J=7.2,1 \mathrm{H}), 6.91-6.85(\mathrm{~m}, 2 \mathrm{H}), 6.8-6.75\left(\mathrm{dd}, J_{2}=2.0, J_{1}=8.8,1 \mathrm{H}\right) ;{ }^{13} \mathrm{C} \mathrm{NMR}(100 \mathrm{MHz}$, DMSO-d $) \delta 182.33,168.86,167.54,148.42,141.97,140.13,132.63,132.18,130.00,128.95$, 128.08, 127.68, 126.97, 114.05, 113.74, 110.97, 99.61; ${ }^{13} \mathrm{C}$ DEPT NMR (100 MHz, DMSO-d 6 ) $\delta$ 132.36, 129.73, 128.69, 127.81, 127.41, 126.70, 113.78, 110.70, 99.34; HRMS (ESI-TOF) m/z [M-H] negative calc'd. for $\mathrm{C}_{21} \mathrm{H}_{13} \mathrm{O}_{3} 313.0870$, found 313.0872. 54\% yield, yellow solid. Melting Point $=275.3{ }^{\circ} \mathrm{C}$

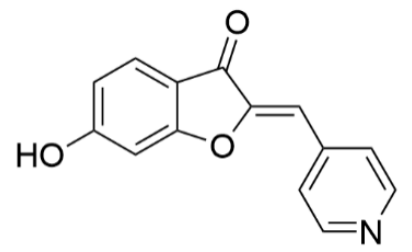

\section{(Z)-6-hydroxy-2-(pyridin-4-ylmethylene)benzofuran-3(2H)-one (SR-F-127)}

${ }^{1} \mathrm{H}$ NMR (400 MHz, DMSO-d6) $\delta$ 11.50-11.35 (bs, 1H), 8.76-8.68 (d, $\left.J=6.0,2 \mathrm{H}\right), 7.91-7.85$ (d, $J=6.0,2 \mathrm{H}), 7.73-7.67(\mathrm{~d}, J=8.4,1 \mathrm{H}), 6.88-6.85(\mathrm{~d}, J=2.0,1 \mathrm{H}), 6.82-6.80(\mathrm{~s}, 1 \mathrm{H}), 6.80-6.76$ 
$\left(\mathrm{dd}, J_{1}=8.4, J_{2}=2.0,1 \mathrm{H}\right) ;{ }^{13} \mathrm{C}$ NMR $\left(100 \mathrm{MHz}, \mathrm{DMSO}-\mathrm{d}_{6}\right) \delta 182.24,169.24,168.13,151.25$, $150.72,140.18,127.29,125.32,114.39,113.18,107.97,99.77 ;{ }^{13} \mathrm{C}$ DEPT NMR (100 MHz, DMSO-d $\left._{6}\right) \delta 151.00,127.04,125.07,114.14,107.72,99.52 ;$ HRMS (ESI-TOF) m/z [M-H] negative calc'd. for $\mathrm{C}_{14} \mathrm{H}_{8} \mathrm{NO}_{3} 238.0510$, found $238.0510 .67 \%$ yield, light yellow solid. Melting Point $=289.5^{\circ} \mathrm{C}$

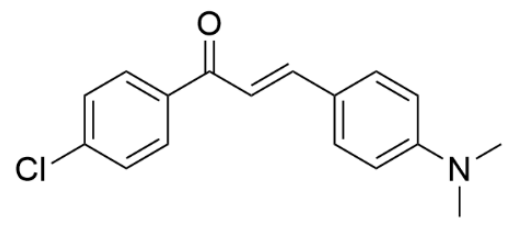

(2E)-1-(4-chlorophenyl)-3-[4-(dimethylamino)phenyl]-2-propen-1-one (SR-F-128)

${ }^{1} \mathrm{H}$ NMR (400 MHz, DMSO-d 6 ) $\delta 8.20-8.14(\mathrm{~d}, J=8.8,2 \mathrm{H}), 7.78-7.61(\mathrm{~m}, 6 \mathrm{H}), 6.81-6.76(\mathrm{~d}, J=$ 8.8, 2H), 3.07-3.03 (s, 6H); ${ }^{13} \mathrm{C}$ NMR (100 MHz, DMSO-d 6 ) $\delta$ 188.36, 153.03, 146.65, 138.31, 137.93, 131.87, 131.04, 129.64, 122.79, 116.56, 112.64, 40.60; ${ }^{13} \mathrm{C}$ DEPT NMR (100 MHz, DMSO-d $_{6}$ ) $\delta 146.65,131.87,131.03,129.64,116.56,112.64,40.60 ;$ HRMS (ESI-TOF) $\mathrm{m} / \mathrm{z}$ $[\mathrm{M}+\mathrm{H}]$ positive calc'd. for $\mathrm{C}_{17} \mathrm{H}_{17} \mathrm{ClNO} 286.0993$, found 286.0986. 64\% yield, orange solid. Melting Point $=140.5^{\circ} \mathrm{C}$<smiles>CN(C)c1ccc(/C=C/C(=O)c2ccc(Br)cc2)cc1</smiles>

(2E)-1-(4-bromophenyl)-3-[4-(dimethylamino)phenyl]-2-propen-1-one (SR-F-129)

${ }^{1} \mathrm{H}$ NMR (400 MHz, DMSO-d 6 ) $\delta$ 8.12-8.05 (d, $\left.J=8.4,2 \mathrm{H}\right), 7.82-7.61(\mathrm{~m}, 6 \mathrm{H}), 6.82-6.75(\mathrm{~d}, J=$ 8.8, 2H), 3.05 (s, 6H); ${ }^{13} \mathrm{C}$ NMR (400 MHz, DMSO-d 6 ) $\delta 188.55,153.03,146.67,138.26,132.58$, 
$131.86,131.16,127.43,122.78,116.53,112.64,40.61 ;{ }^{13} \mathrm{C}$ DEPT NMR (100 MHz, DMSO-d 6 ) $\delta$ 146.68, 132.59, 131.88, 131.17, 116.53, 112.63, 40.60; HRMS (ESI-TOF) m/z [M+H] positive calc'd. for $\mathrm{C}_{17} \mathrm{H}_{17} \mathrm{BrNO} 330.0488$, found $330.0478 .71 \%$ yield, orange solid. Melting Point $=143.6$ ${ }^{\circ} \mathrm{C}$

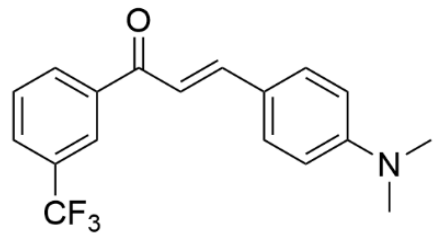

(2E)-[1-(3-trifluoromethyl)-phenyl]-3-[4-(dimethylamino)phenyl]-2-propen-1-one (SR-F-130)

${ }^{1} \mathrm{H}$ NMR (400 MHz, DMSO-d 6 ) $\delta 8.50-8.43(\mathrm{~d}, J=7.6,1 \mathrm{H}), 8.42-8.38(\mathrm{~s}, 1 \mathrm{H}), 8.07-8.00(\mathrm{~d}, J=$ 8.0, 1H), 7.88-7.74 (m, 5H), 6.84-6.76 (d, $J=9.2,2 \mathrm{H}), 3.22-3.02(\mathrm{~s}, 6 \mathrm{H}) ;{ }^{13} \mathrm{C}$ NMR $(100 \mathrm{MHz}$, DMSO-d $)_{6} \delta 188.18,153.13,147.32,140.02,133.08,132.10,130.86,130.59,130.28,129.72(\mathrm{~d}$, $J=3.8), 126.27,125.43$ (d, $J=3.8), 123.56,122.73,116.29,112.59,40.59 ;{ }^{13} \mathrm{C}$ DEPT NMR (100 MHz, DMSO-d $)_{6} \delta 147.32,133.08,132.10,130.86,129.72$ (d, $\left.J=3.8\right), 125.45,116.29,112.59$, 40.59; HRMS (ESI-TOF) m/z [M+H] positive calc'd. for $\mathrm{C}_{18} \mathrm{H}_{17} \mathrm{~F}_{3} \mathrm{NO} 320.1257$, found 320.1248. $58 \%$ yield, orange yellow solid. Melting Point $=83.3^{\circ} \mathrm{C}$

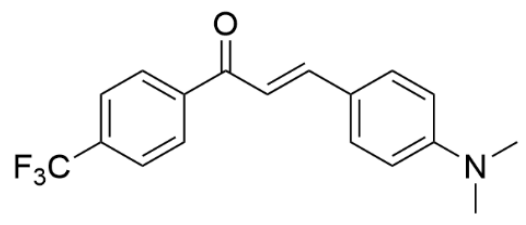

(2E)-[1-(4-trifluoromethyl)-phenyl]-3-[4-(dimethylamino)phenyl]-2-propen-1-one (SR-F-131)

${ }^{1} \mathrm{H}$ NMR $\left(400 \mathrm{MHz}, \mathrm{CDCl}_{3}\right) \delta 8.20-8.05(\mathrm{~d}, J=8.4,2 \mathrm{H}), 7.94-7.68(\mathrm{~m}, 3 \mathrm{H}), 7.64-7.45(\mathrm{~d}, J=8.8$, $2 \mathrm{H}), 7.35-7.16(\mathrm{~d}, J=15.2,1 \mathrm{H}), 6.85-6.58(\mathrm{~d}, J=8.4,2 \mathrm{H}), 3.12-3.01(\mathrm{~s}, 6 \mathrm{H}) ;{ }^{13} \mathrm{C}$ NMR $(100$ 
$\left.\mathrm{MHz}, \mathrm{CDCl}_{3}\right) \delta 190.02,152.67,147.47,142.45,133.40$ (q), 131.05, 128.90, 125.83, 125.52, 122.66, 116.67, 112.18, 40.44; ${ }^{13} \mathrm{C}$ DEPT NMR (100 MHz, $\left.\mathrm{CDCl}_{3}\right) \delta 147.47,131.04,128.89$, 125.83, 116.66, 112.16, 40.44; HRMS (ESI-TOF) $\mathrm{m} / \mathrm{z}[\mathrm{M}+\mathrm{H}]$ positive calc'd. for $\mathrm{C}_{18} \mathrm{H}_{17} \mathrm{~F}_{3} \mathrm{NO}$ 320.1257 , found $320.1247 .86 \%$ yield, orange yellow solid. Melting Point $=142.1{ }^{\circ} \mathrm{C}$

\section{References:}

1. Laurent Lunven, Hugues Bonnet, Samir Yahiaoui, Wei Yi, Laurène Da Costa, Marine Peuchmaur, Ahcène Boumendjel, and Sabine Chierici. Disruption of Fibers from the Tau Model AcPHF6 by Naturally Occurring Aurones and Synthetic Analogues. ACS Chemical Neuroscience 2016, 7 (7), 995-1003; DOI: 10.1021/acschemneuro.6b00102

2. Sabrina Okombi, Delphine Rival, Sébastien Bonnet, Anne-Marie Mariotte, Eric Perrier, and Ahcène Boumendjel. Discovery of Benzylidenebenzofuran-3(2H)-one (Aurones) as Inhibitors of Tyrosinase Derived from Human Melanocytes. J. Med. Chem. 2006, 49, 329333. DOI: $10.1021 / \mathrm{jm} 050715 \mathrm{i}$

3. Suvitha Shyam, Siddig Ibrahim Abdelwahab, Mohammed Ali -Al Mamary, and Syam Mohan. Synthesis of chalcones with anticancer activities. Molecules 2012, 17, 6179-6195; doi:10.3390/molecules17066179

4. Chunlin Zhuang, Wen Zhang, Chunquan Sheng, Wannian Zhang, Chengguo Xing, and Zhenyuan Miao. Chalcone: A privileged structure in medicinal chemistry. Chemical Reviews 2017117 (12), 7762-7810. DOI: 10.1021/acs.chemrev.7b00020 
${ }^{1} \mathrm{H},{ }^{13} \mathrm{C},{ }^{13} \mathrm{C}$-DEPT \& ${ }^{19} \mathrm{~F}$ NMR spectra and analytical HPLC traces of ERO1 $\alpha$ inhibitor compounds

\section{${ }^{1}$ H NMR of SR-F-114}

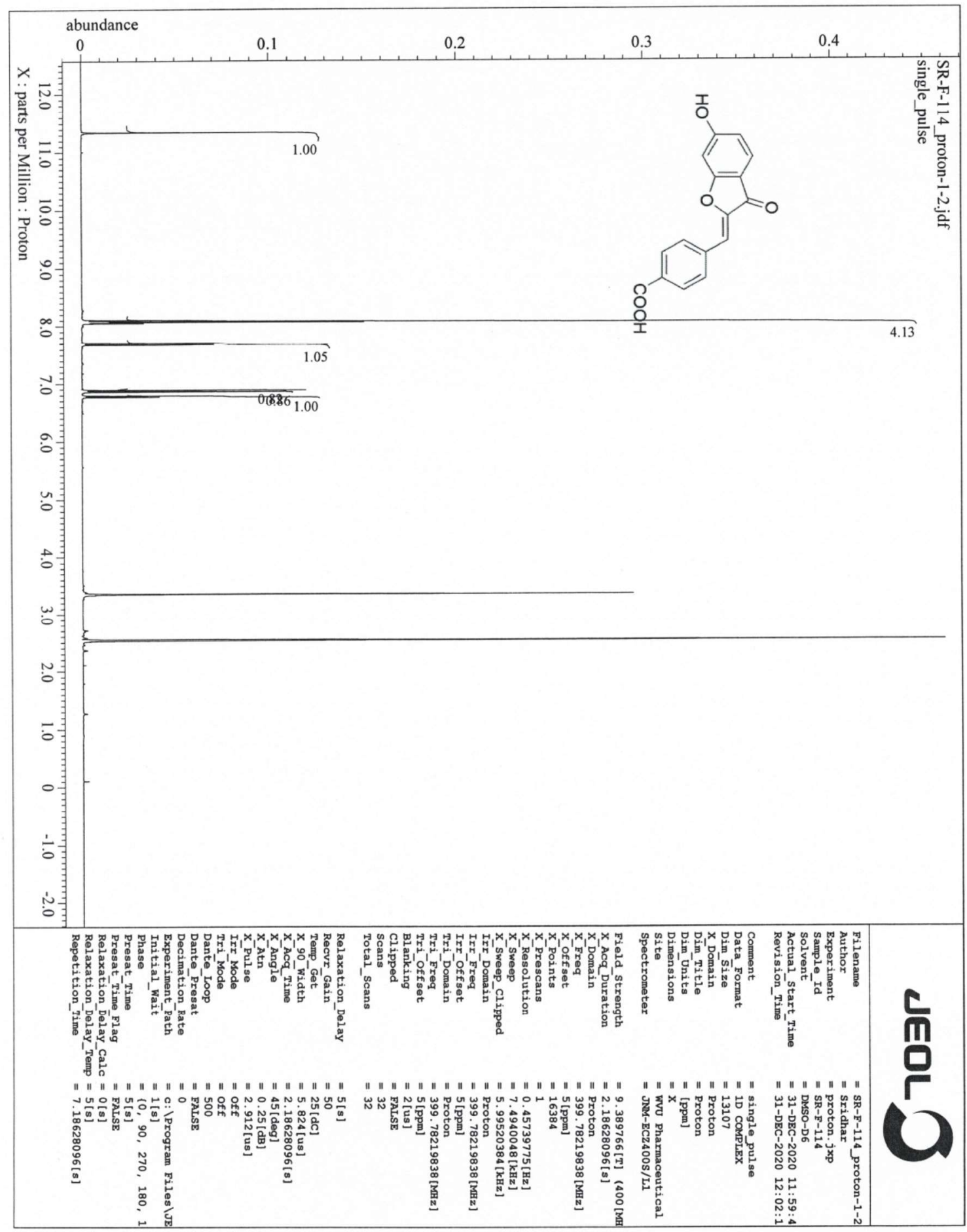




\section{${ }^{13}$ C NMR of SR-F-114}

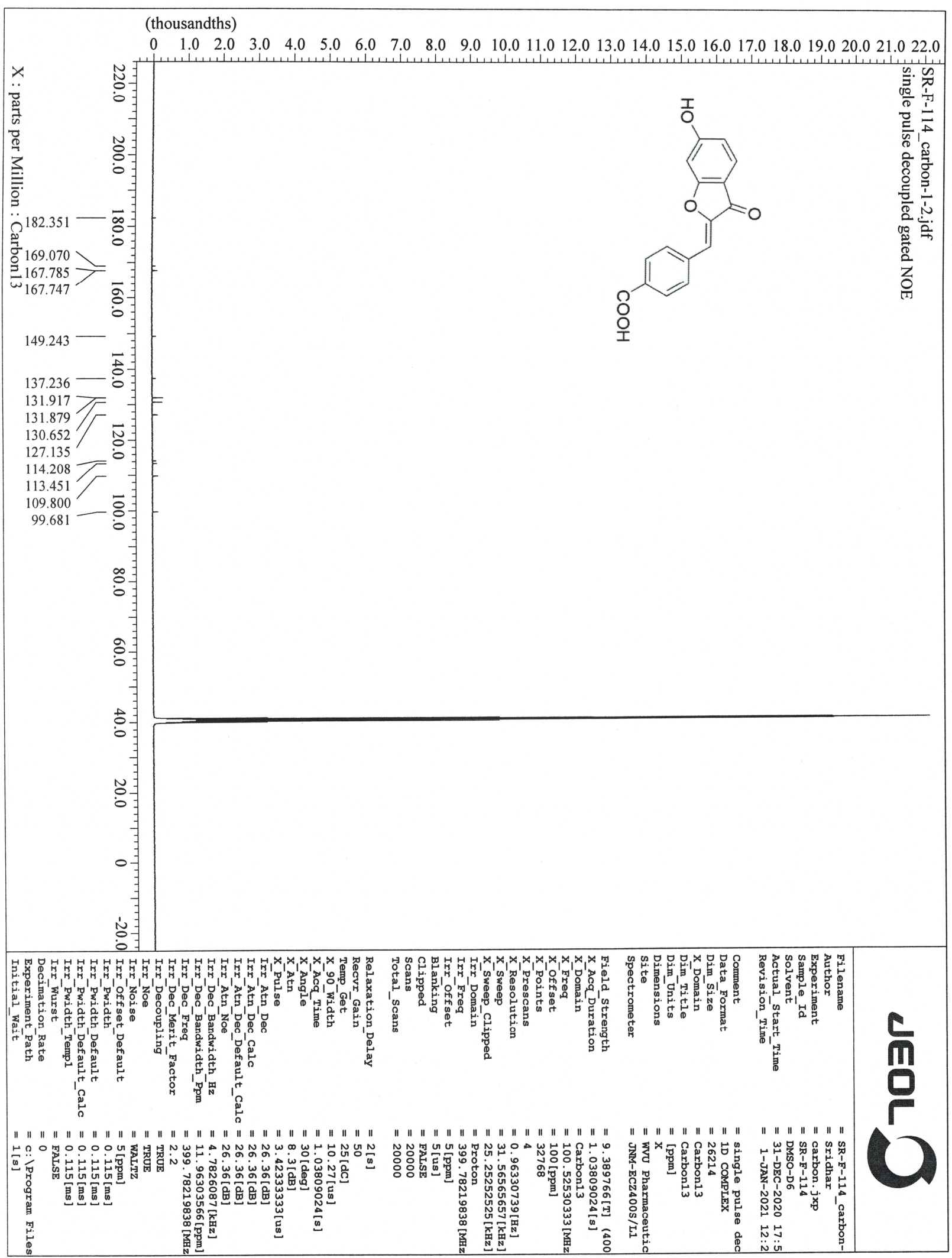




\section{${ }^{13}$ C DEPT NMR of SR-F-114}

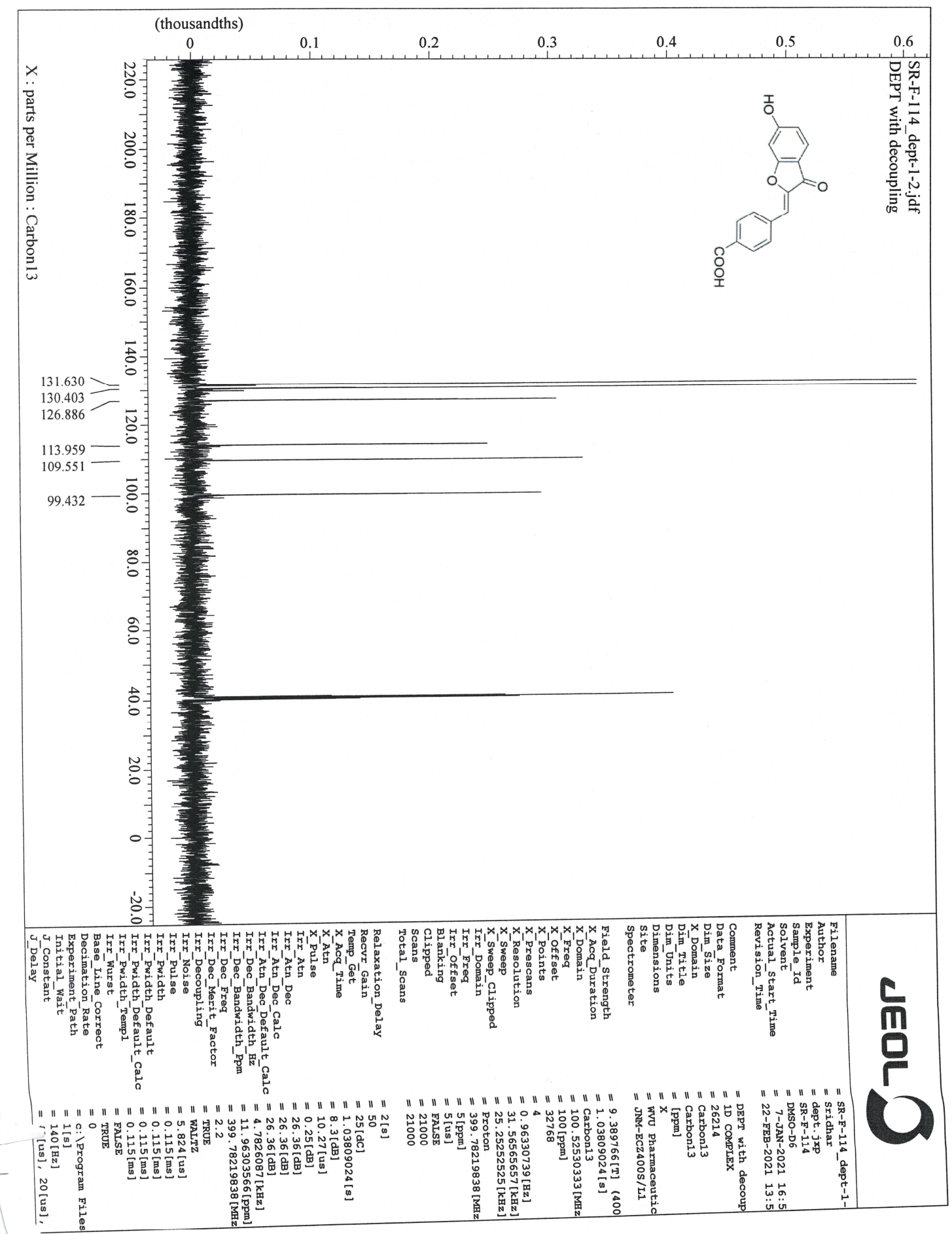




\section{Analytical HPLC Chromatogram of SR-F-114}

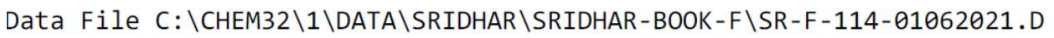

Sample Name: SR-F-114
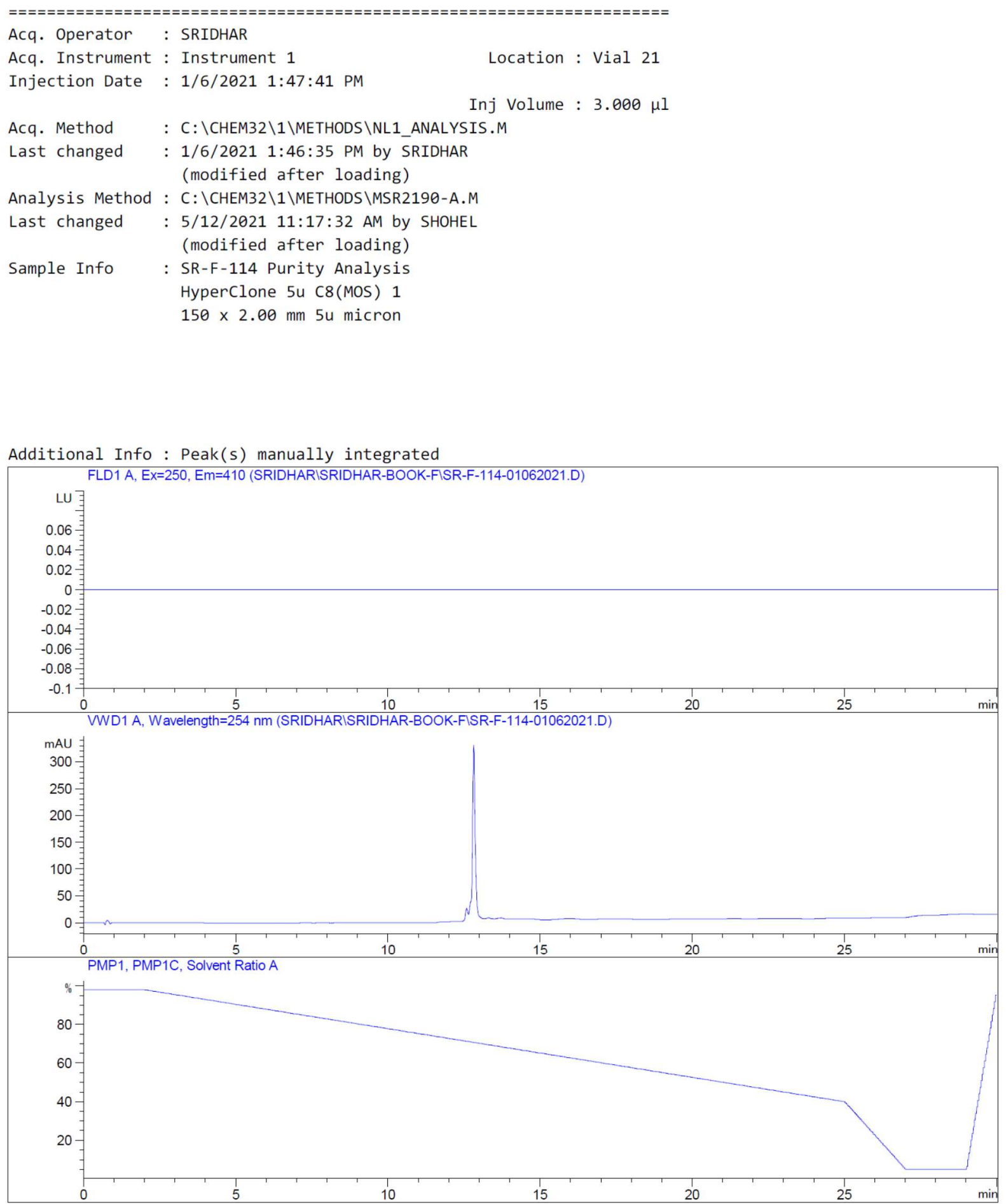


\section{${ }^{1} \mathrm{H}$ NMR of SR-F-115}

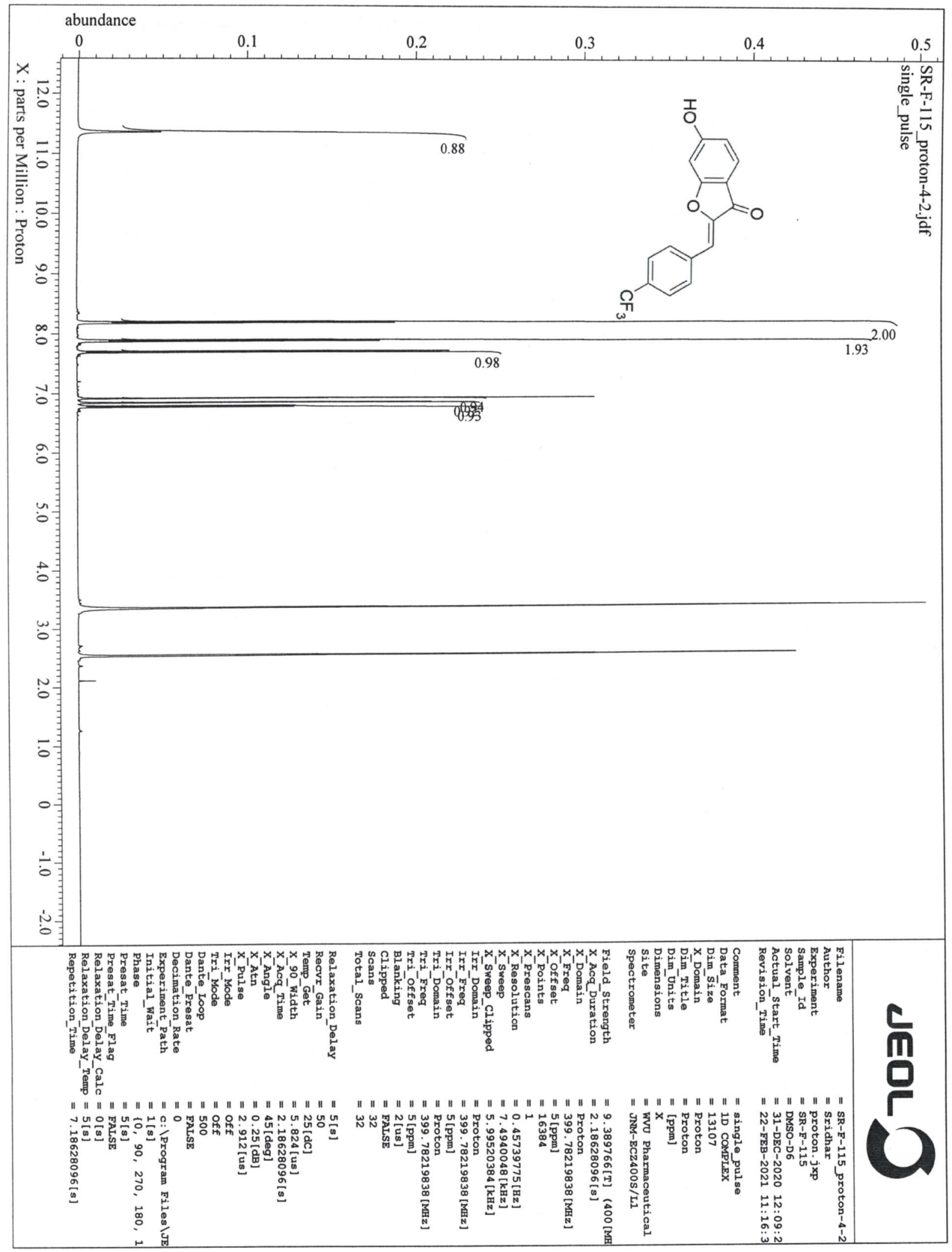




\section{${ }^{13}$ C NMR of SR-F-115}

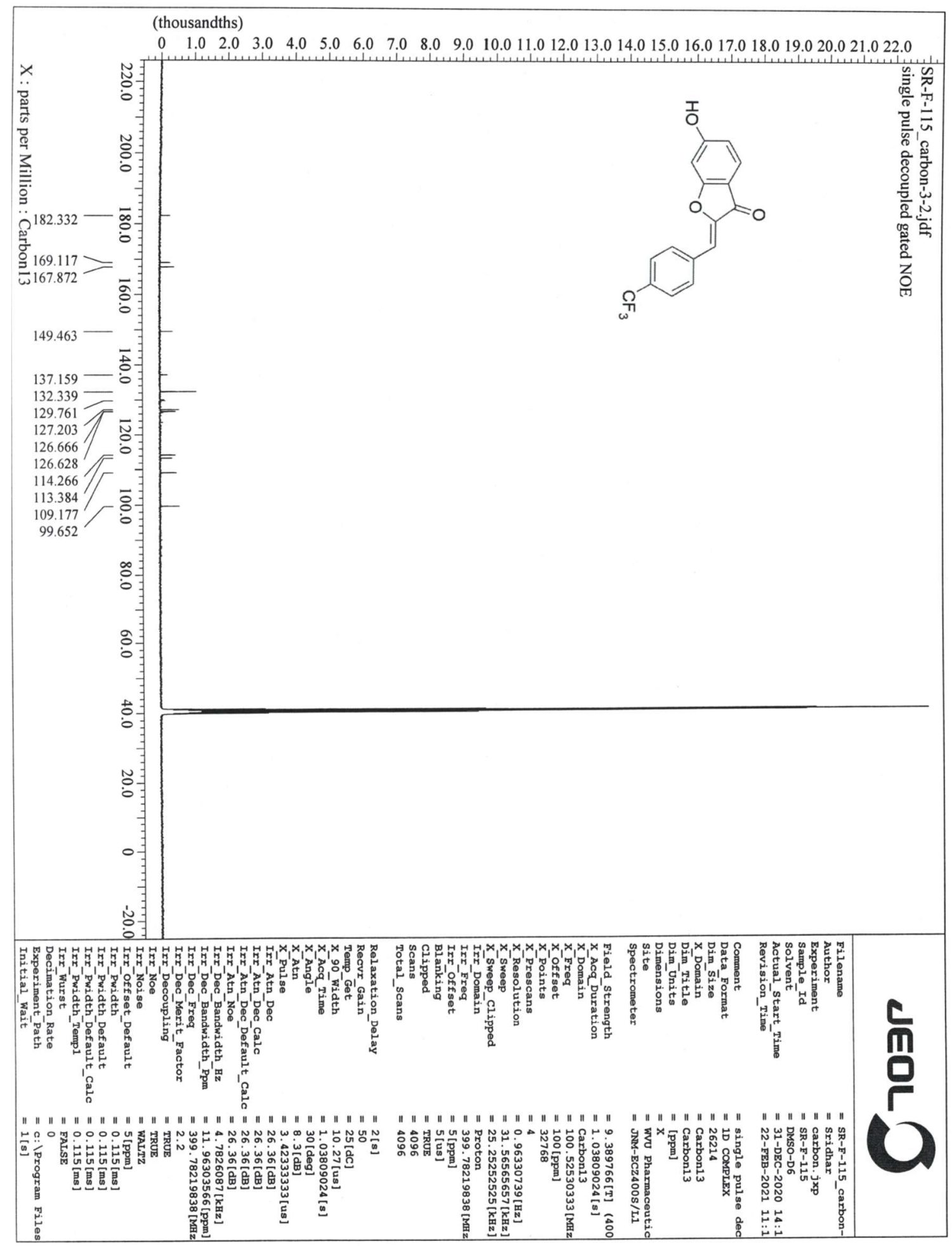




\section{${ }^{13}$ C DEPT NMR of SR-F-115}

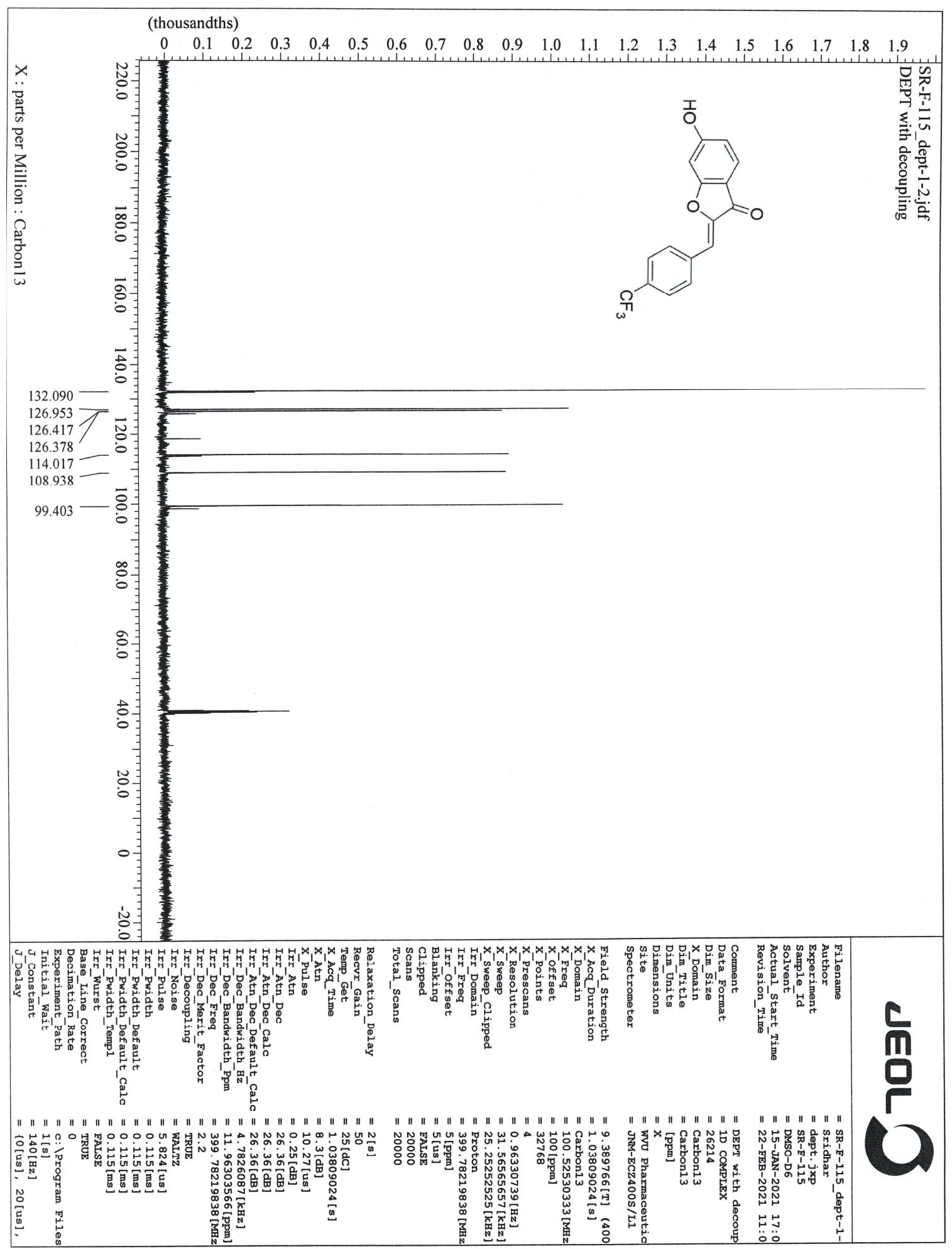


${ }^{19}$ F NMR of SR-F-115

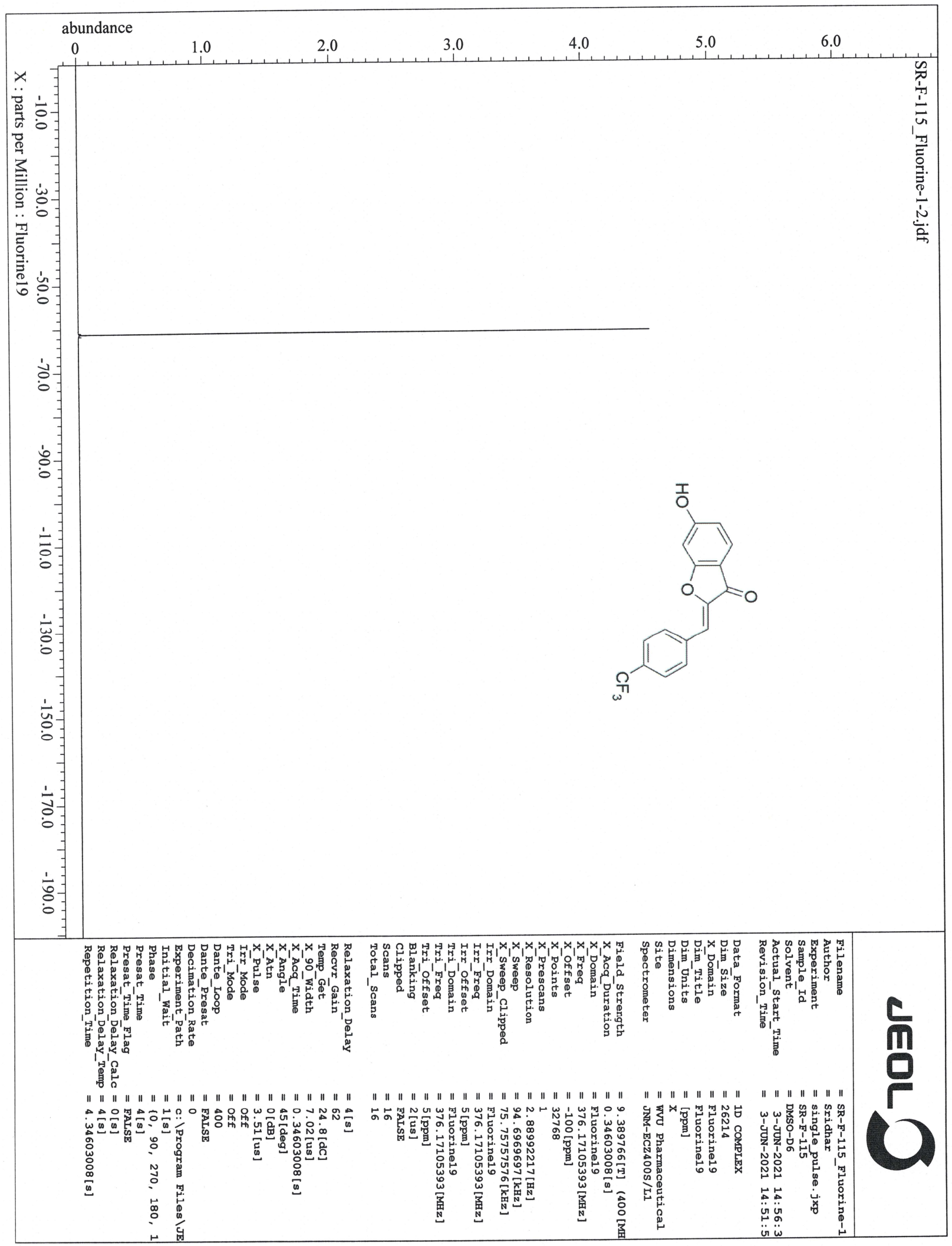




\section{Analytical HPLC Chromatogram of SR-F-115}

Data File C: \CHEM32\1\DATA\SRIDHAR\SRIDHAR-BOOK-F\SR-F-115-01042021.D

Sample Name: SR-F-115

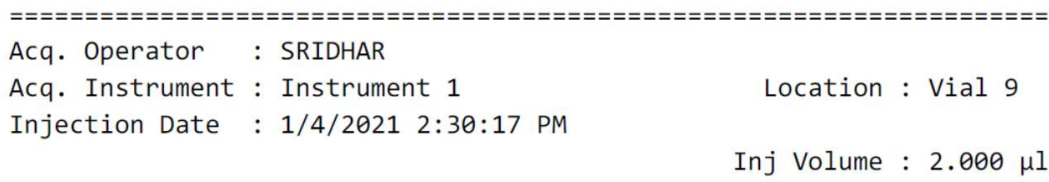

Acq. Method : C: \CHEM32\1\METHODS\NL1_ANALYSIS.M

Last changed : 12/28/2020 11:54:05 AM by SRIDHAR

Analysis Method: C: \CHEM32\1\METHODS\MSR2190-A.M

Last changed : 5/12/2021 11:16:33 AM by SHOHEL

(modified after loading)

Sample Info : SR-F-115 Analysis [ NMR PURE]

HyperClone $5 \mathrm{u}$ C8(MOS) 1

$150 \times 2.00 \mathrm{~mm} 5 \mathrm{u}$ micron

Additional Info : Peak(s) manually integrated

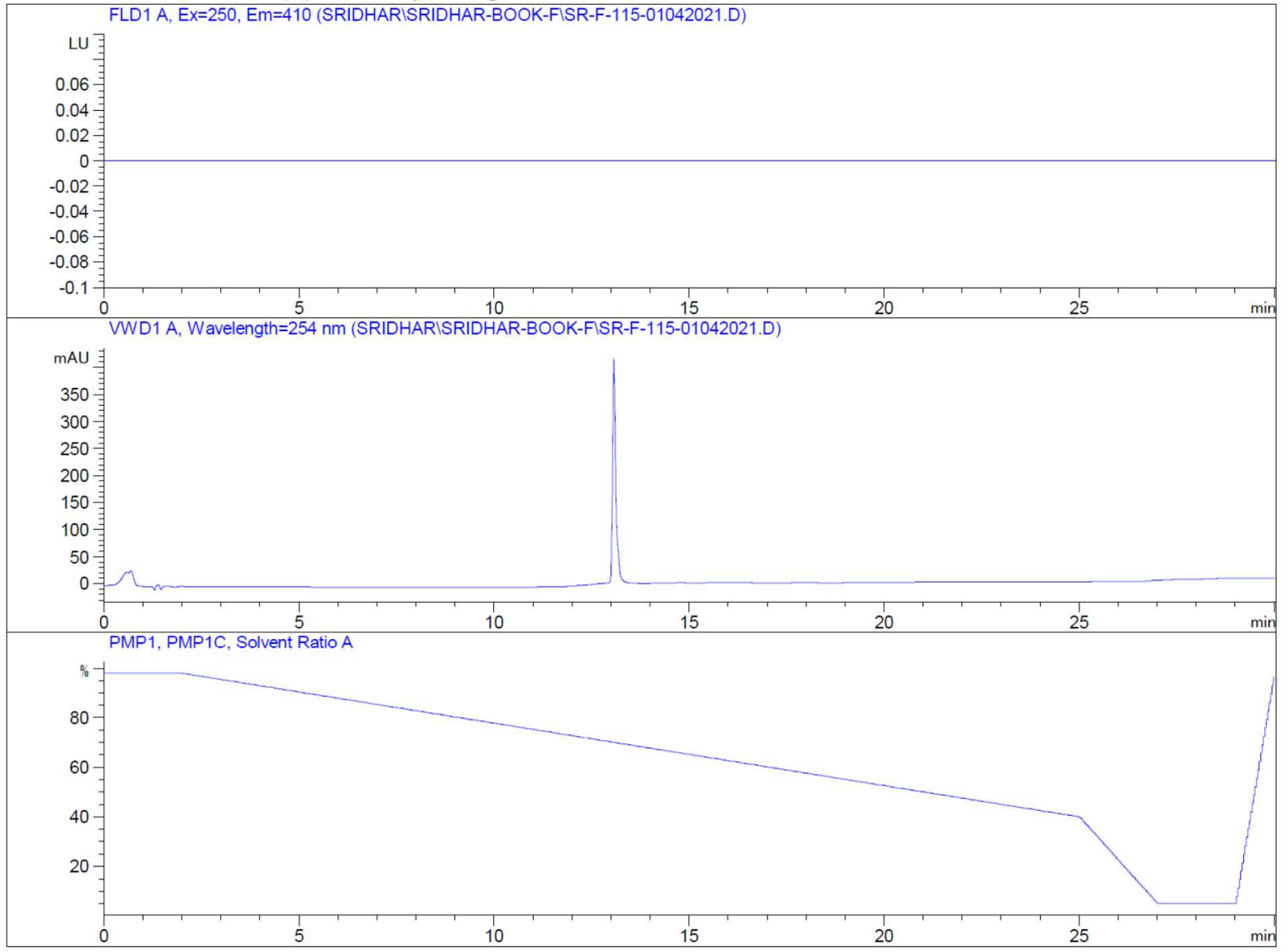




\section{${ }^{1} \mathrm{H}$ NMR of SR-F-119}

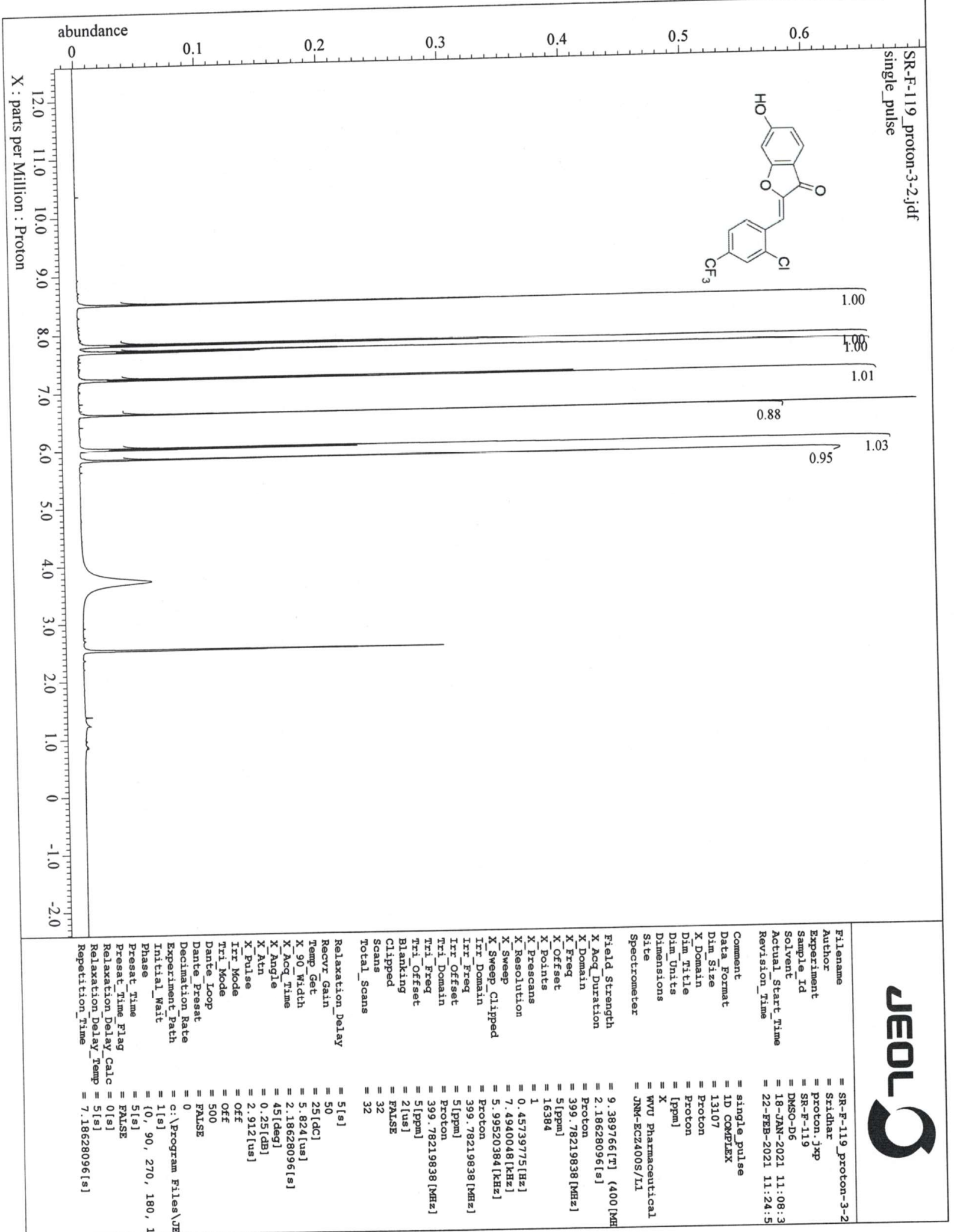




\section{${ }^{13}$ C NMR of SR-F-119}

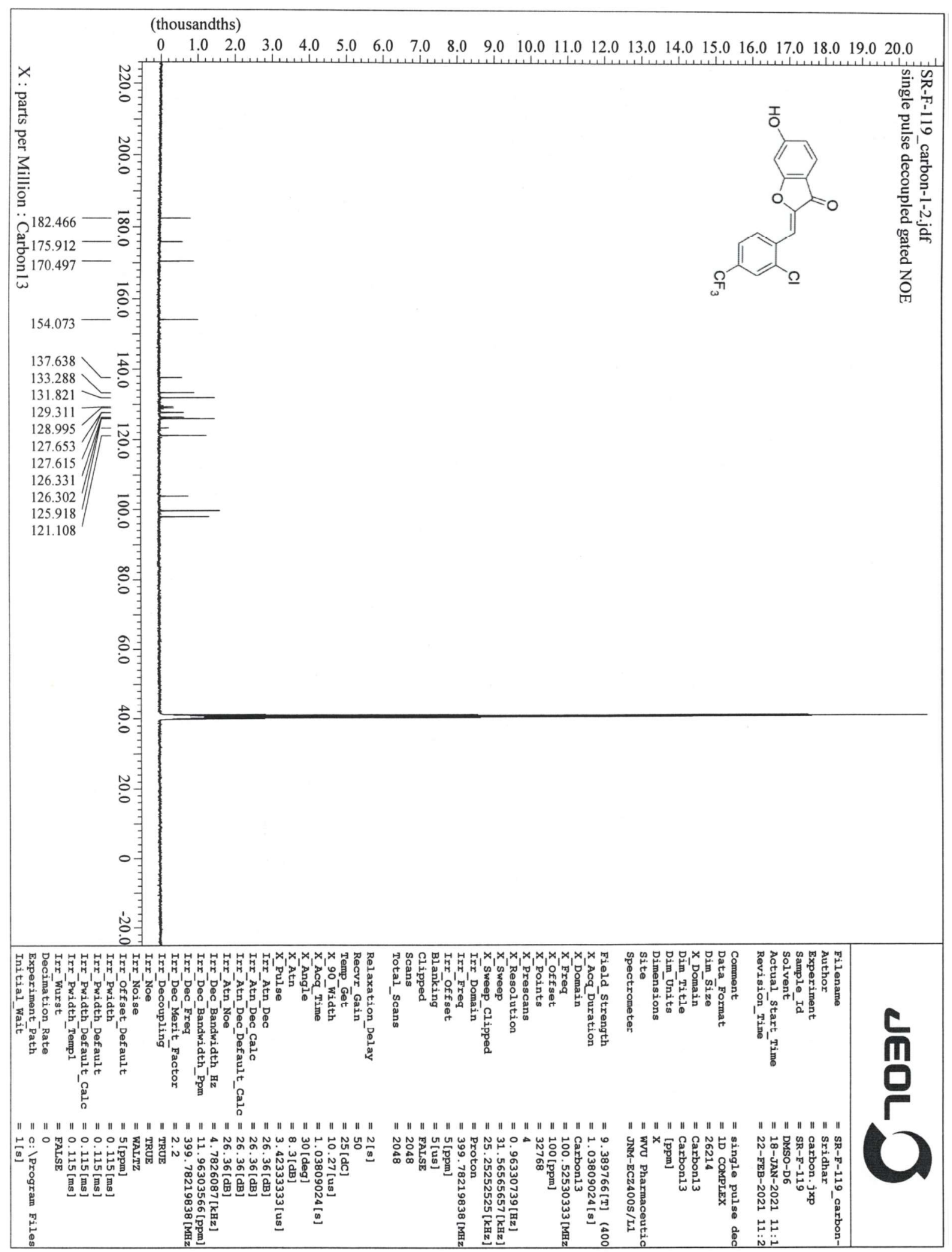




\section{${ }^{13}$ C DEPT NMR of SR-F-119}

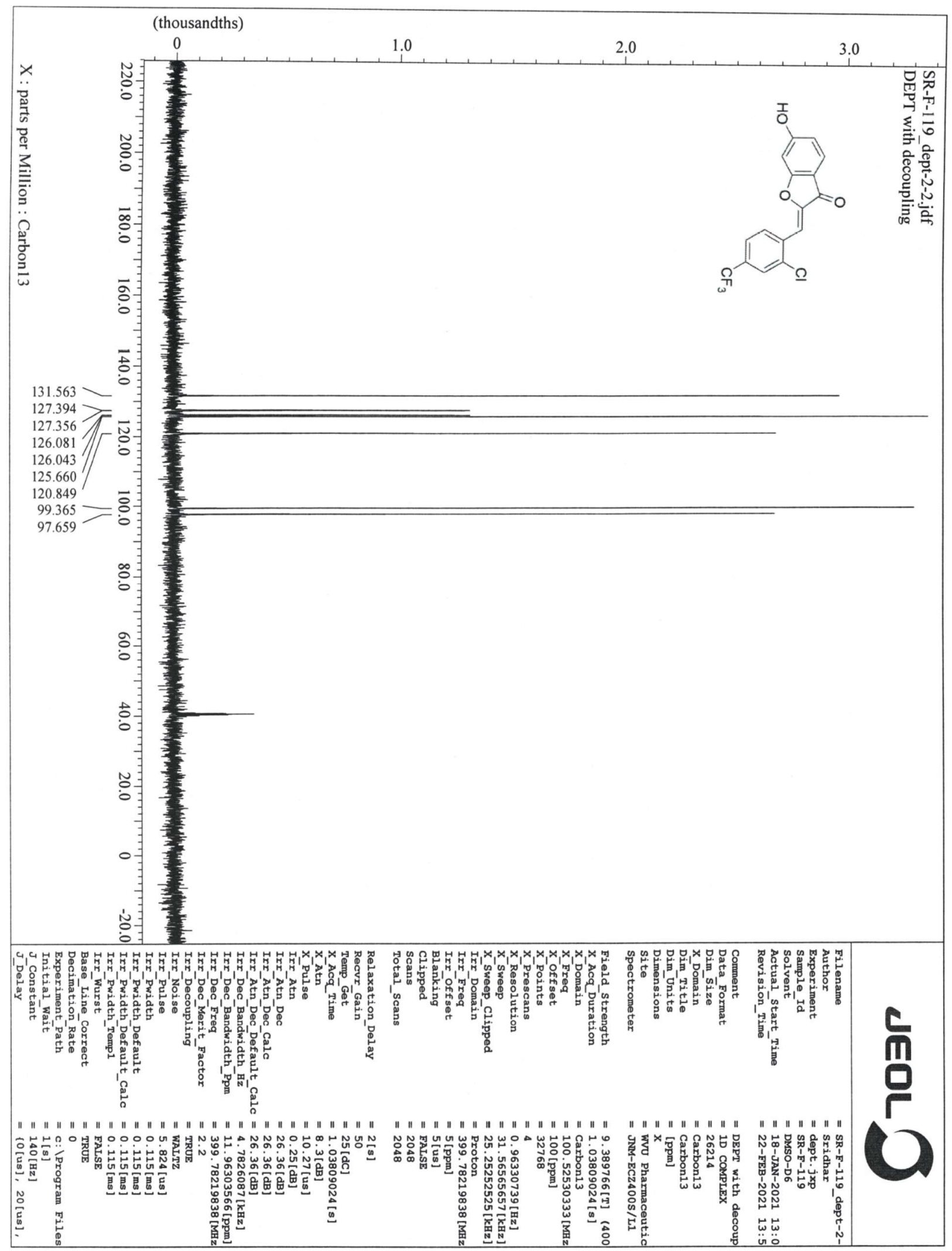


${ }^{19}$ F NMR of SR-F-119

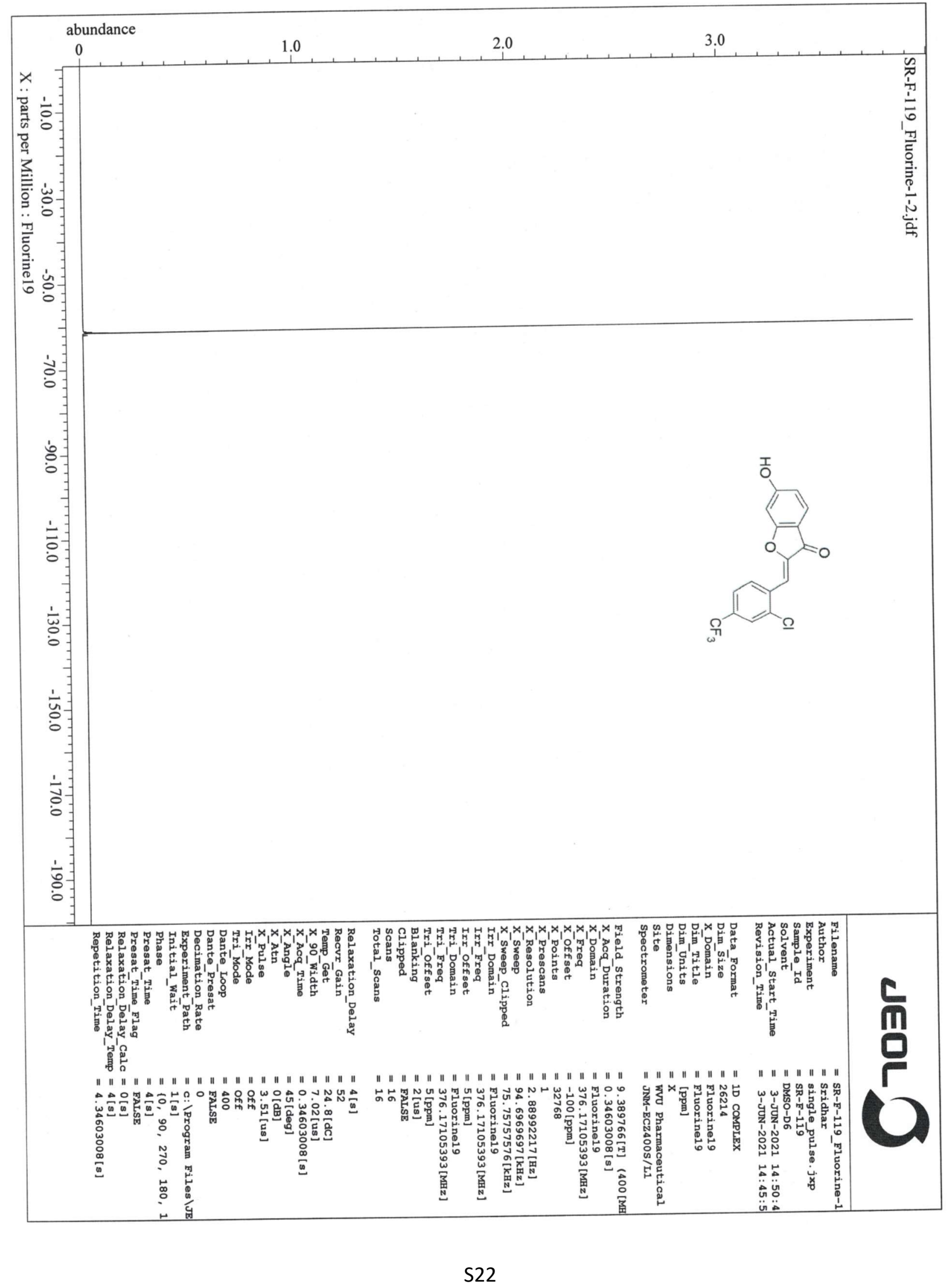




\section{Analytical HPLC Chromatogram of SR-F-119}

Data File C: \CHEM32\1\DATA \SRIDHAR\SRIDHAR-B0OK-F\SR-F-119-03192021.D

Sample Name: SR-F-119
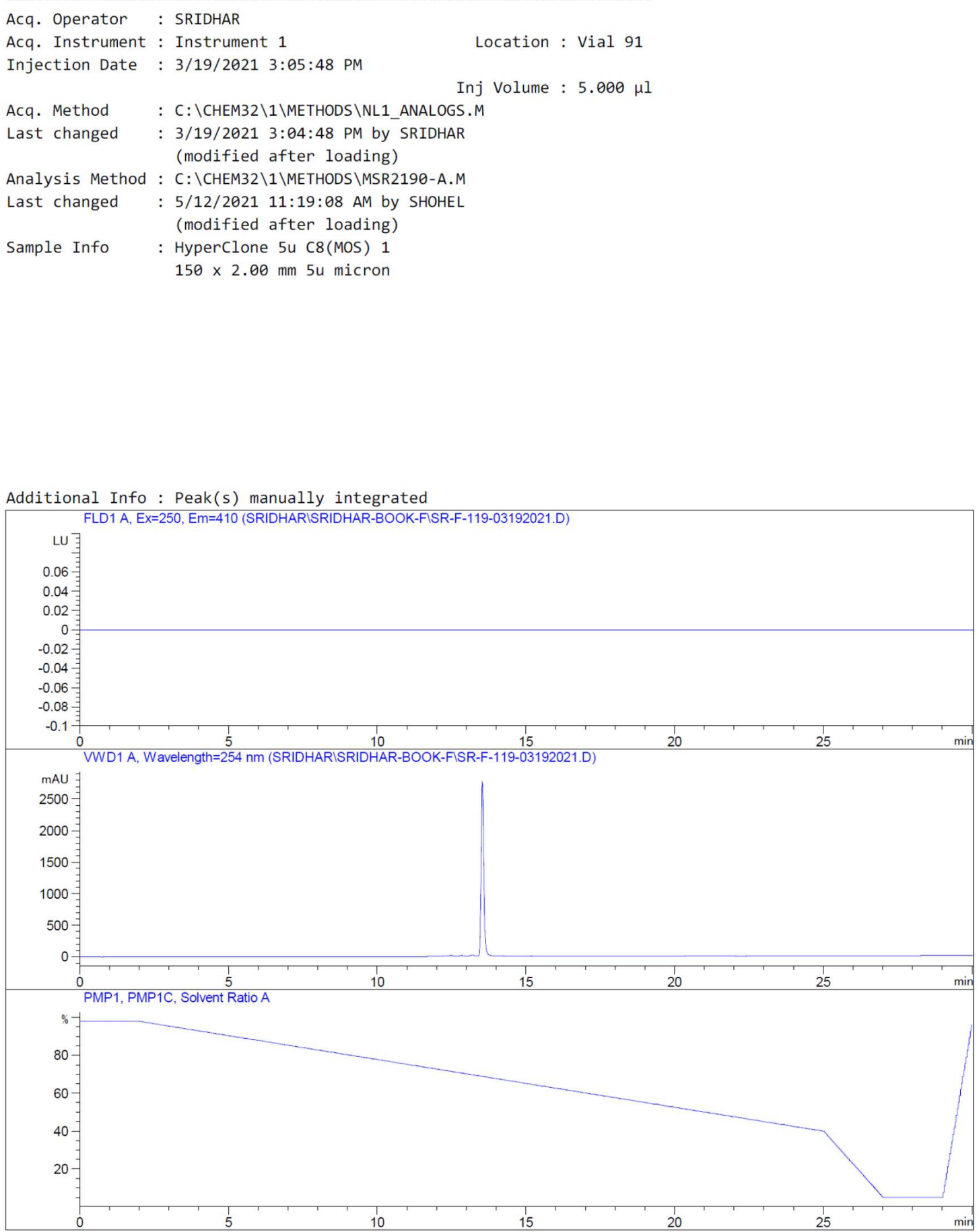


\section{${ }^{1} \mathrm{H}$ NMR of SR-F-125}

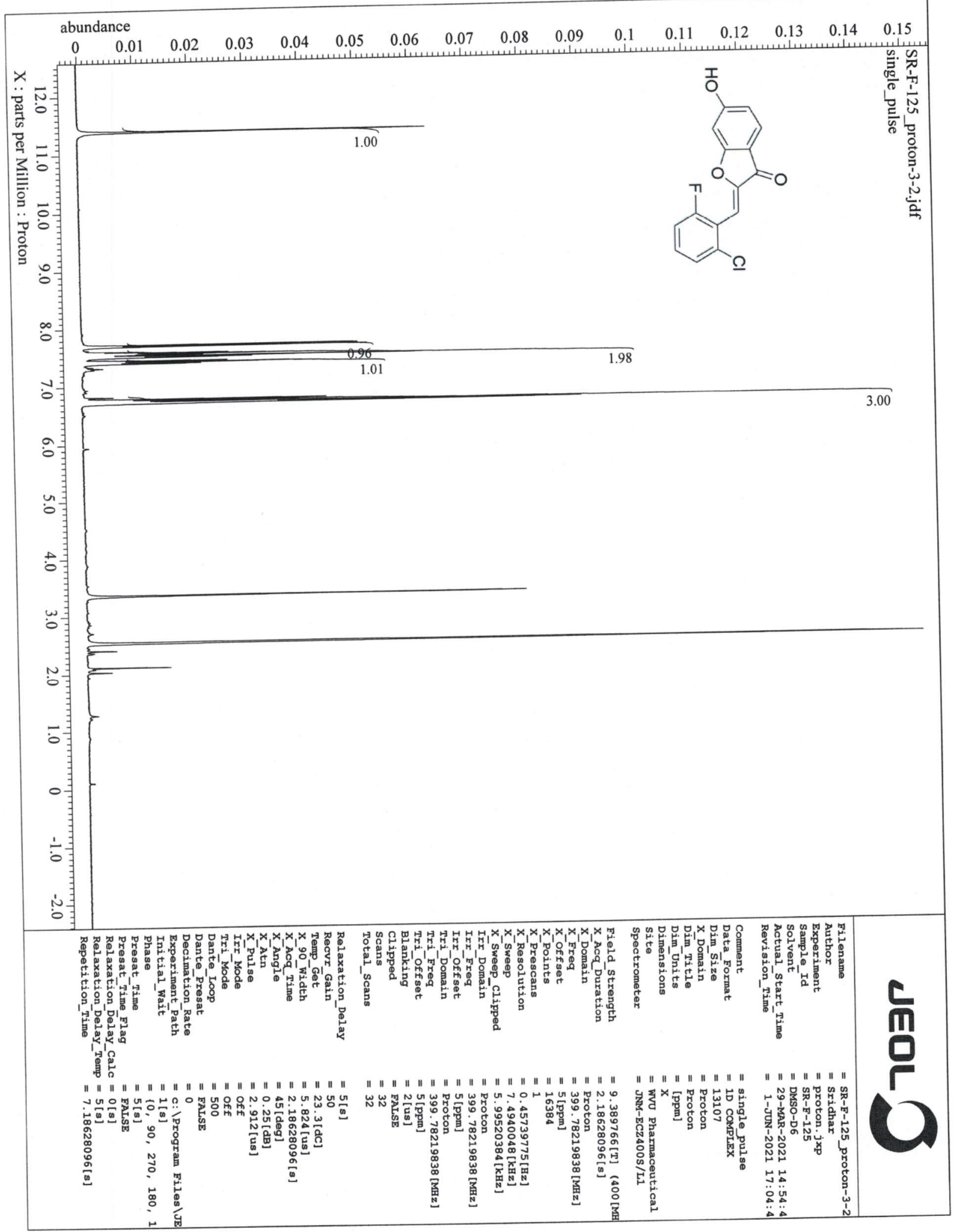


${ }^{13}$ C NMR of SR-F-125

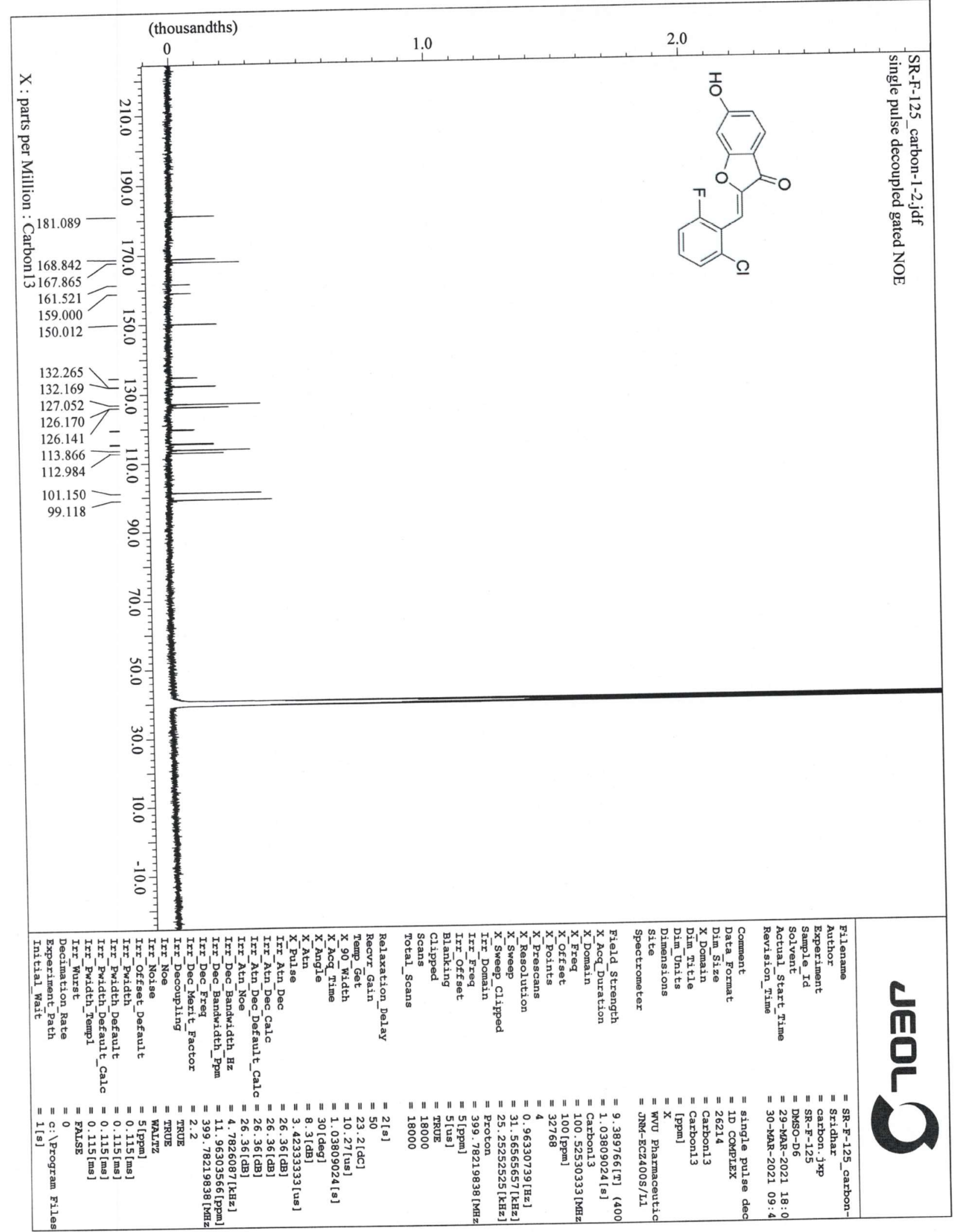


${ }^{13}$ C DEPT NMR of SR-F-125

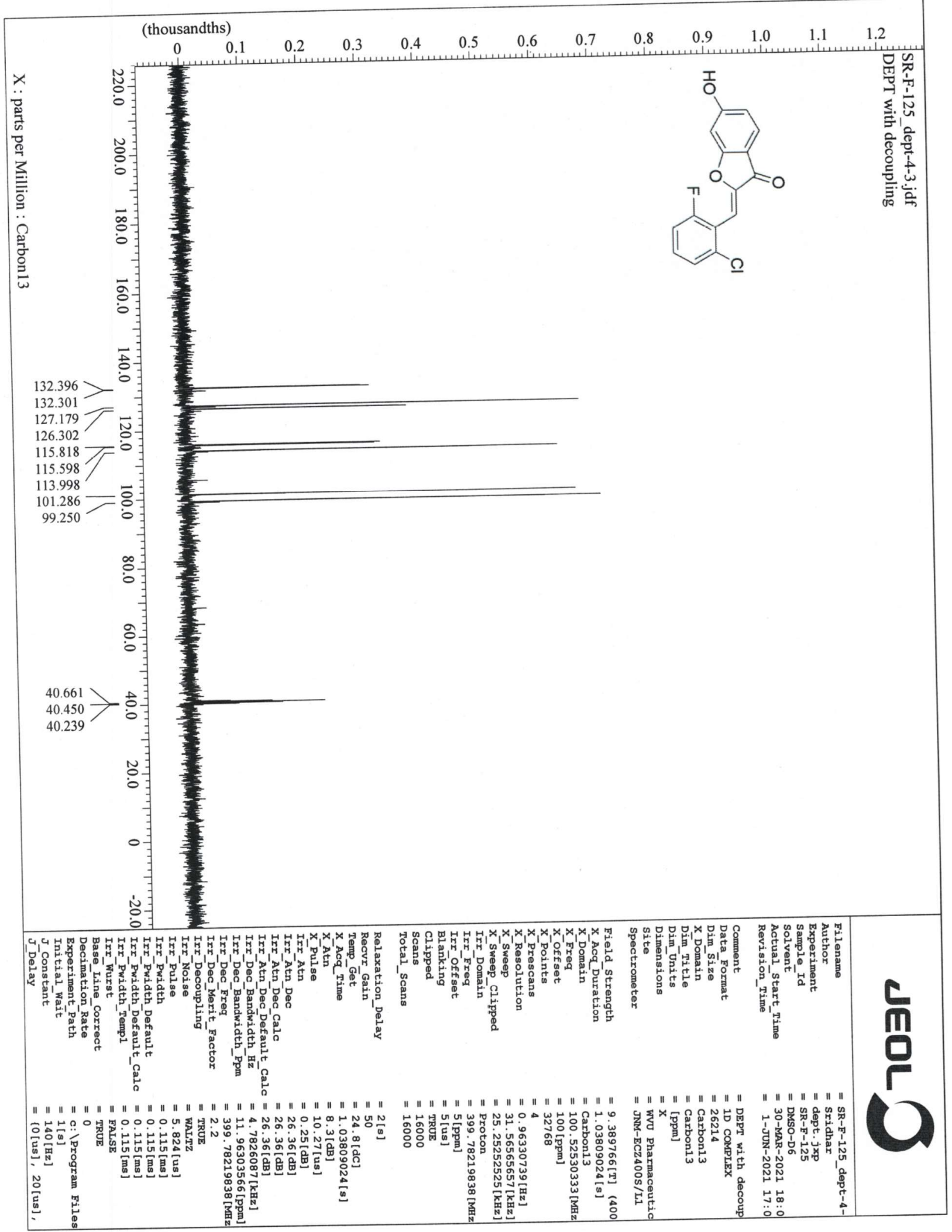


${ }^{19}$ F NMR of SR-F-125

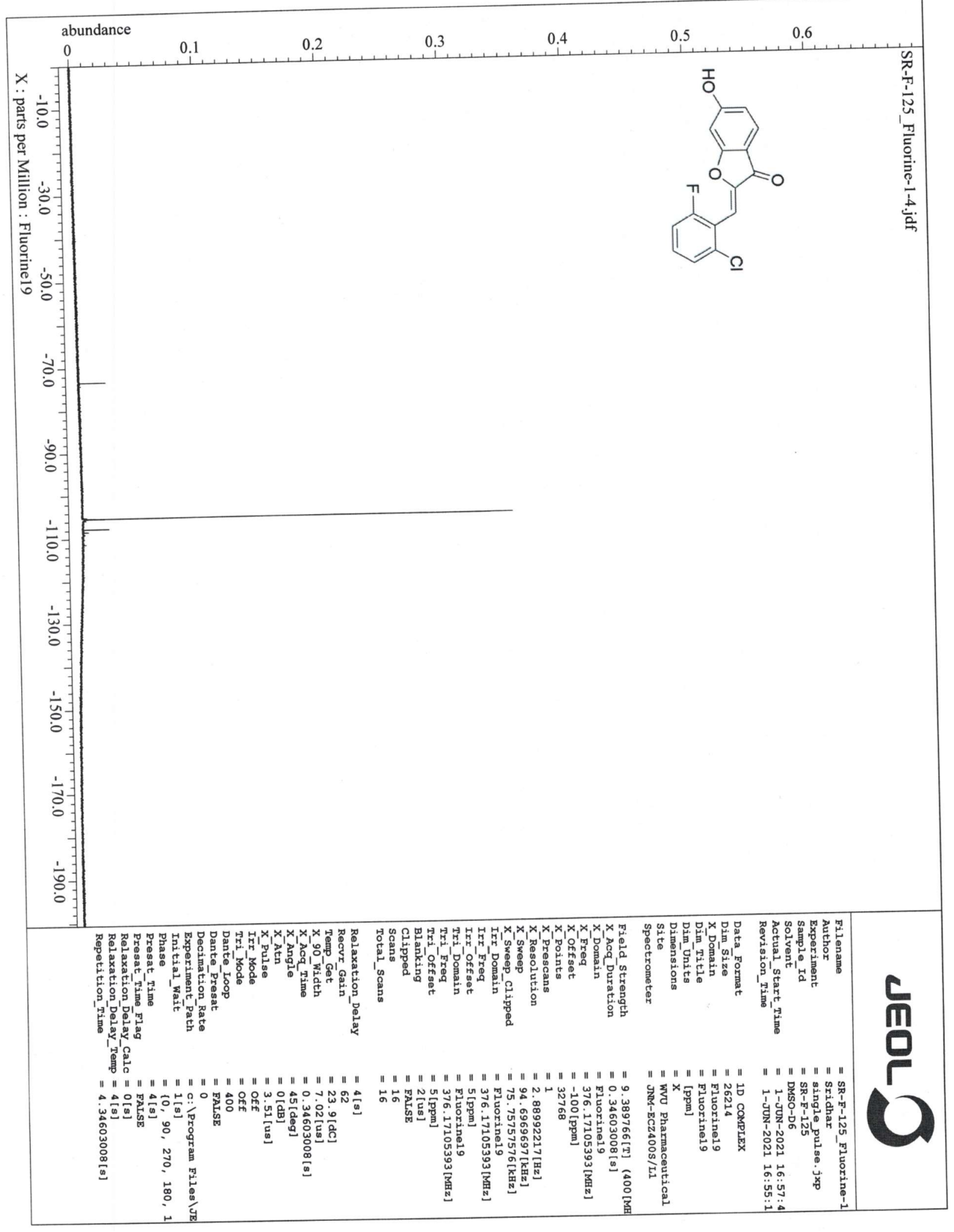




\section{Analytical HPLC Chromatogram of SR-F-125}

Data File C: \CHEM32\1\DATA \SRIDHAR \SR-F-125-FR-4-03292021.D

Sample Name: SR-F-125
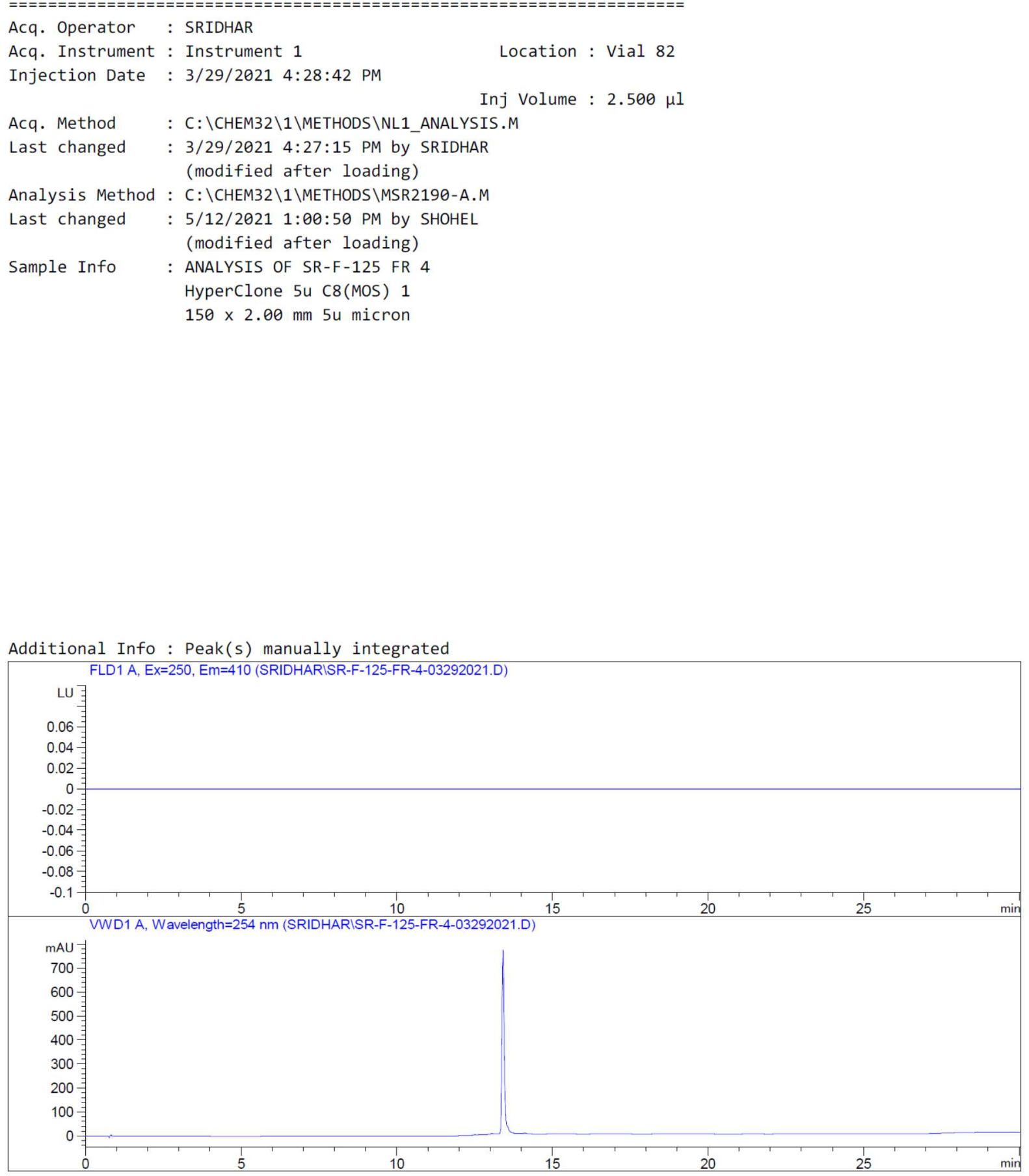


\section{${ }^{1}$ H NMR of SR-F-126}

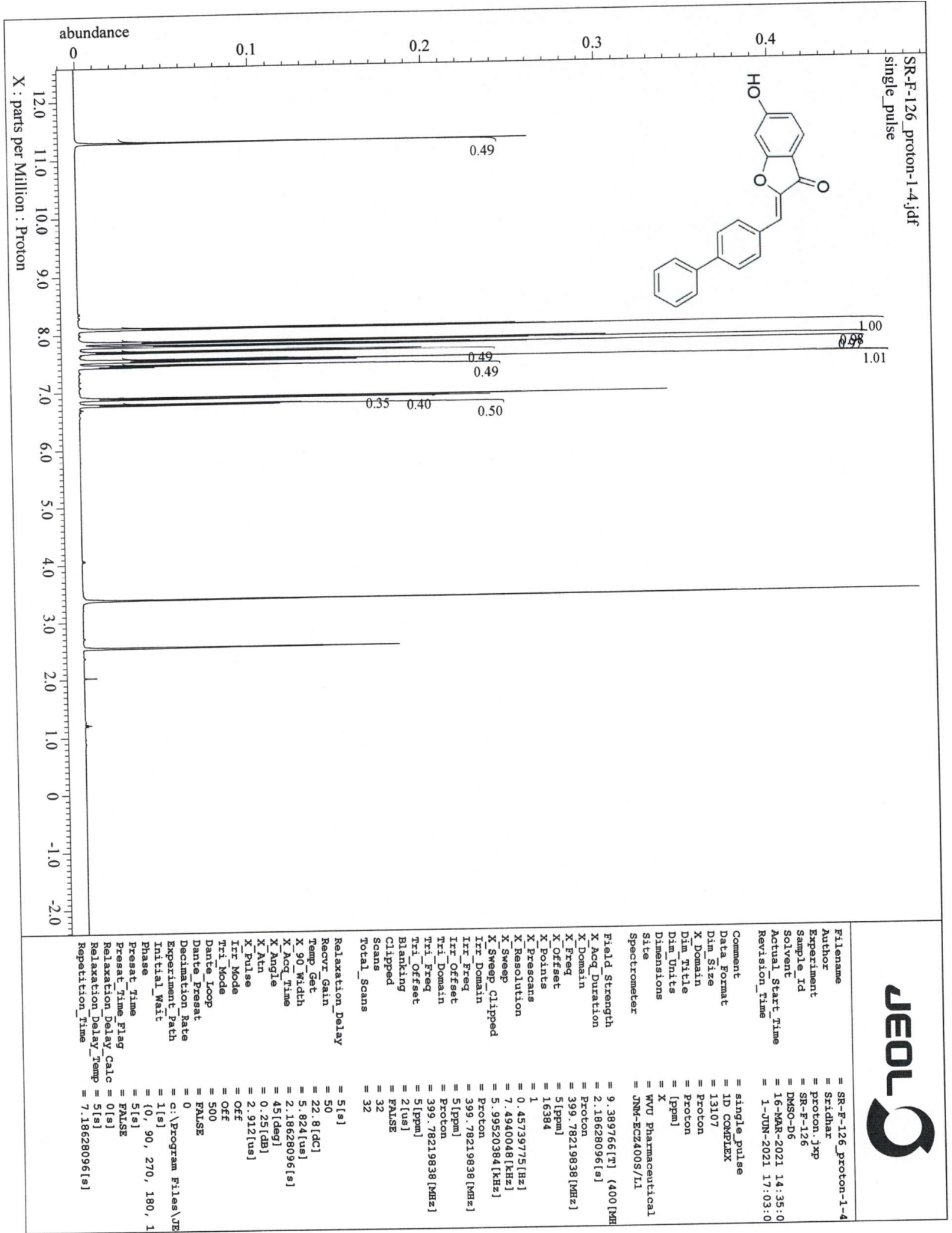




\section{${ }^{13}$ C NMR of SR-F-126}

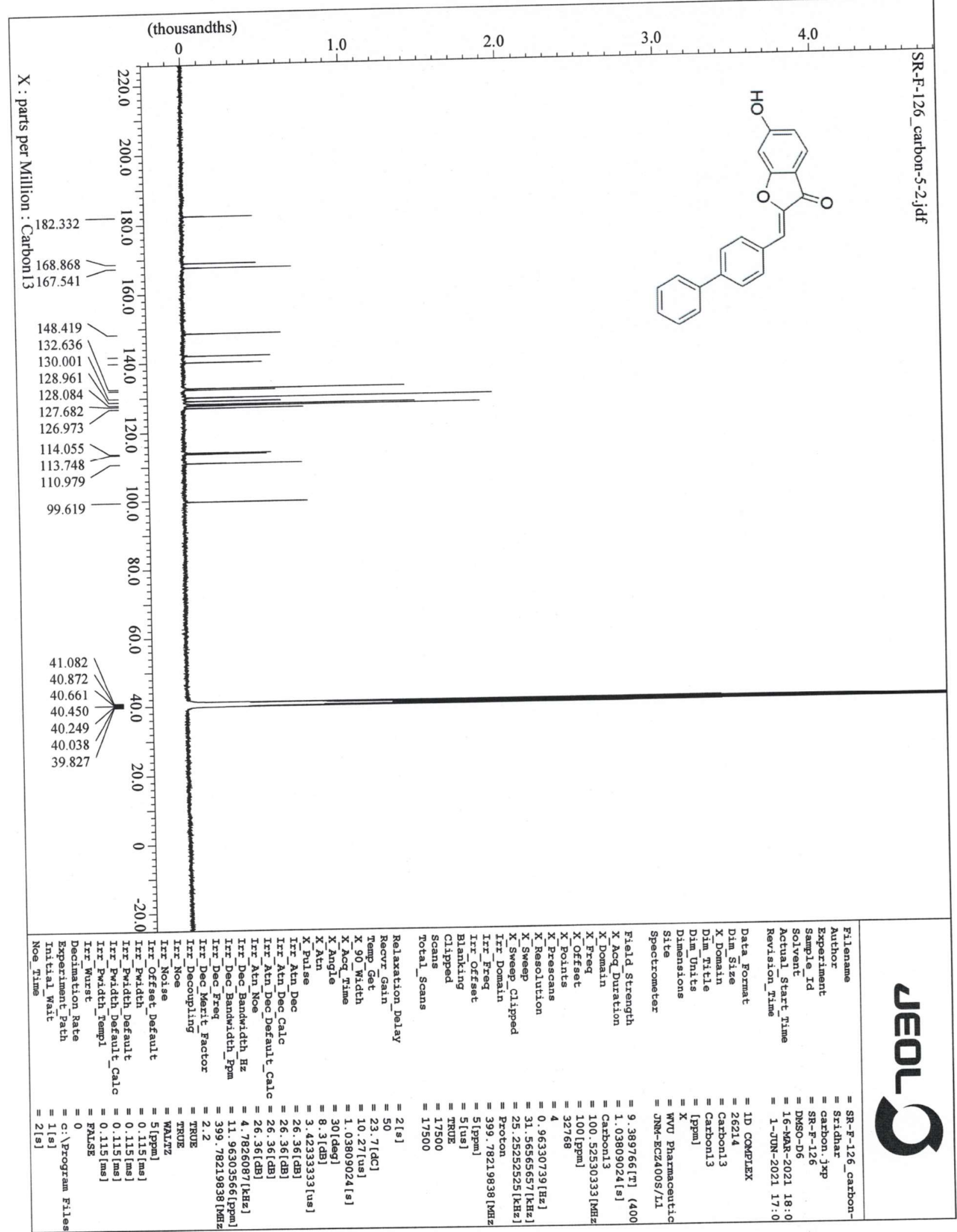


${ }^{13}$ C DEPT NMR of SR-F-126

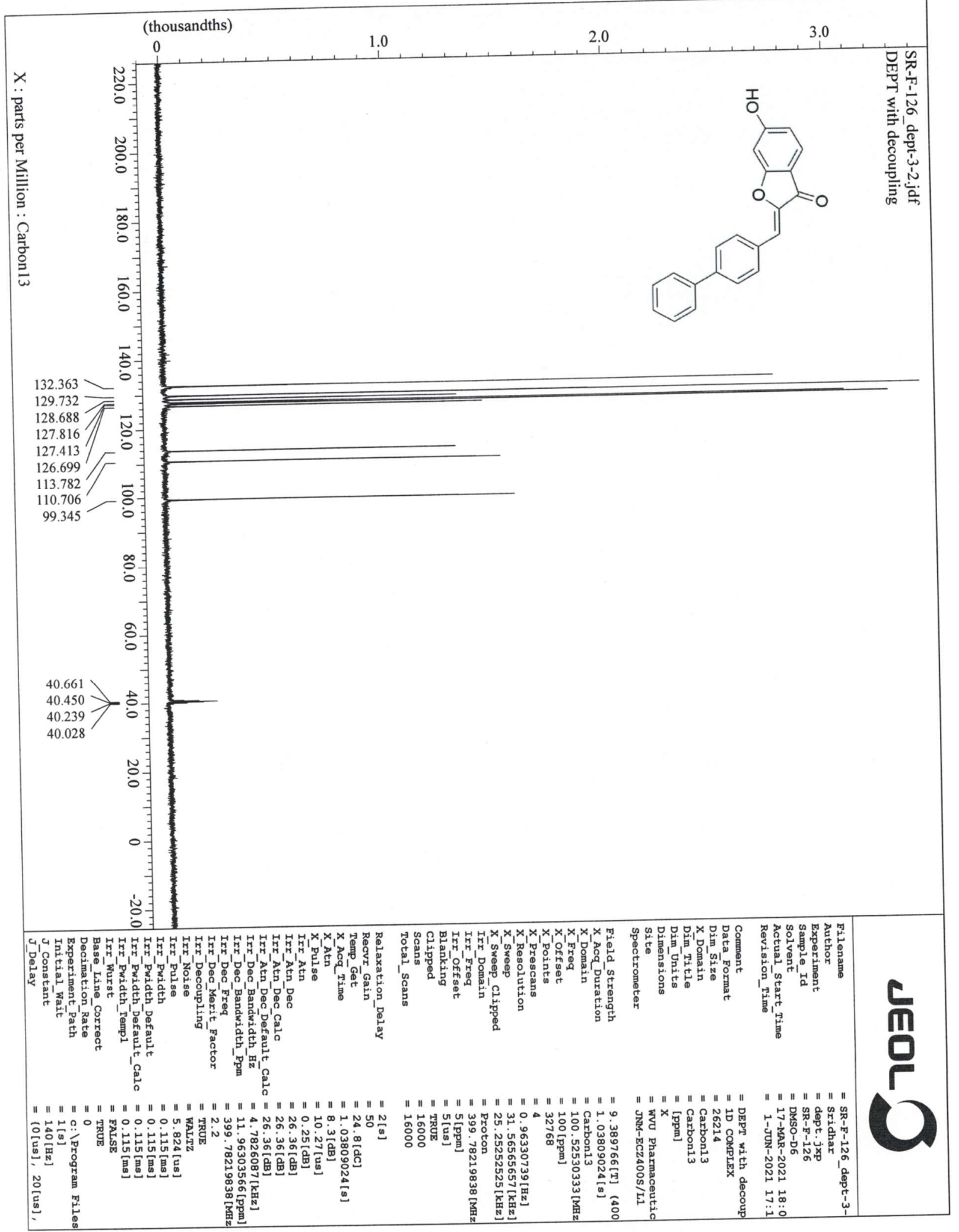




\section{Analytical HPLC Chromatogram of SR-F-126}

Data File C: \CHEM32\1\DATA \SRIDHAR\SR-F-126-2NDRUN-06072021.D

Sample Name: SR-F-126

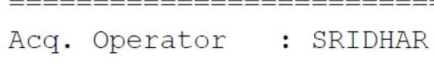

Acq. Instrument : Instrument 1

Injection Date : 6/7/2021 1:05:11 PM

Acq. Method

Last changed

Analysis Method

Last changed

Method Info

Sample Info

: NL1 ANALYSIS

: SR-F-126-06072021
Inj Volume : $2.000 \mu 1$

: C: \CHEM32 \1\METHODS \NL1ANALYSIS_NEW.M

: 6/7/2021 1:03:43 PM by SRIDHAR

: C: \CHEM32\1\METHODS \SCOTT-CI987.M

: 6/4/2021 4:29:37 PM by SCOTT

HyperClone $5 \mathrm{u}$ C8 (MOS) 1

$150 \times 2.00 \mathrm{~mm} 5 \mathrm{u}$ micron

Additional Info: Peak(s) manually integrated

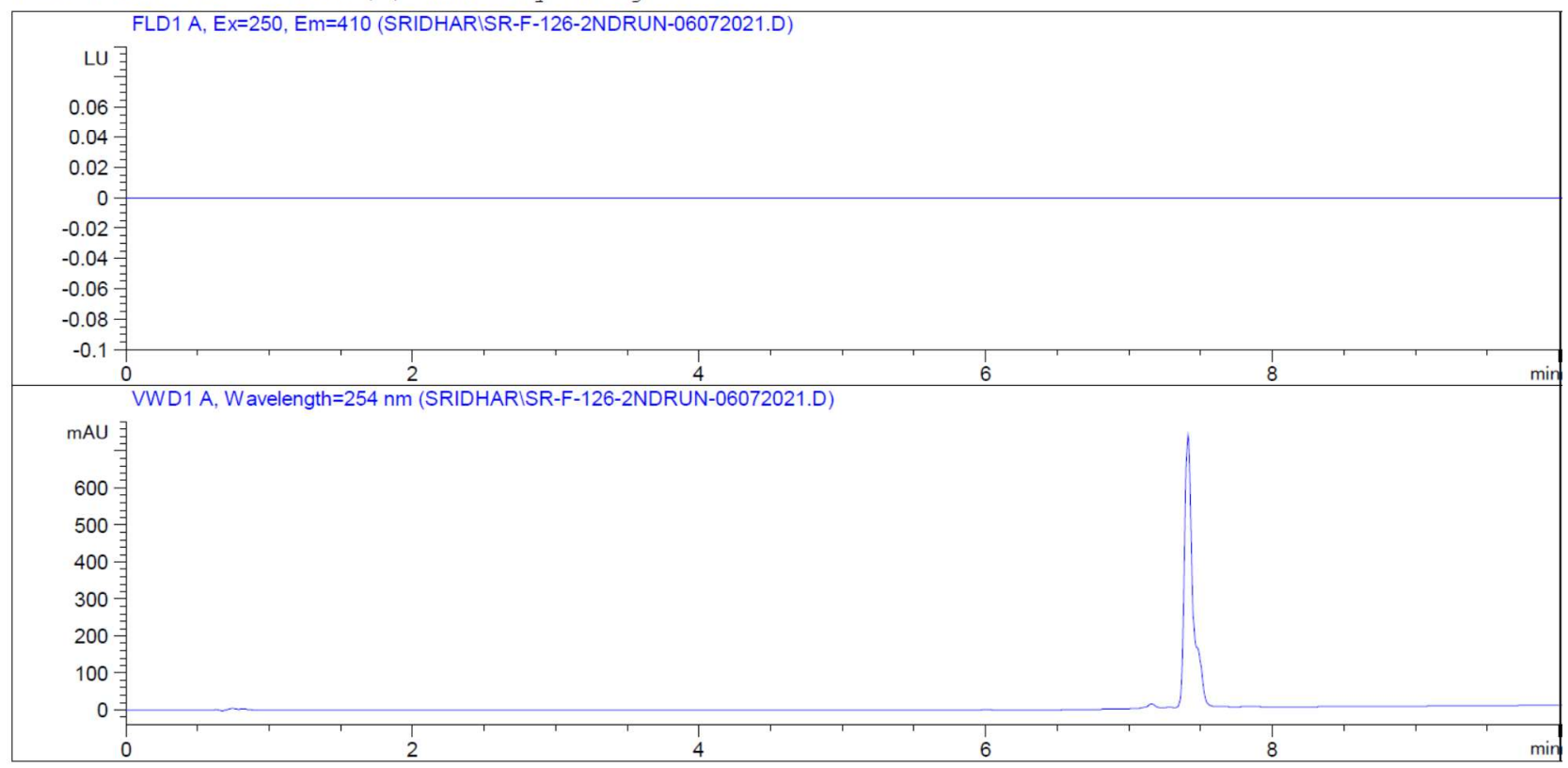




\section{${ }^{1} \mathrm{H}$ NMR of SR-F-127}

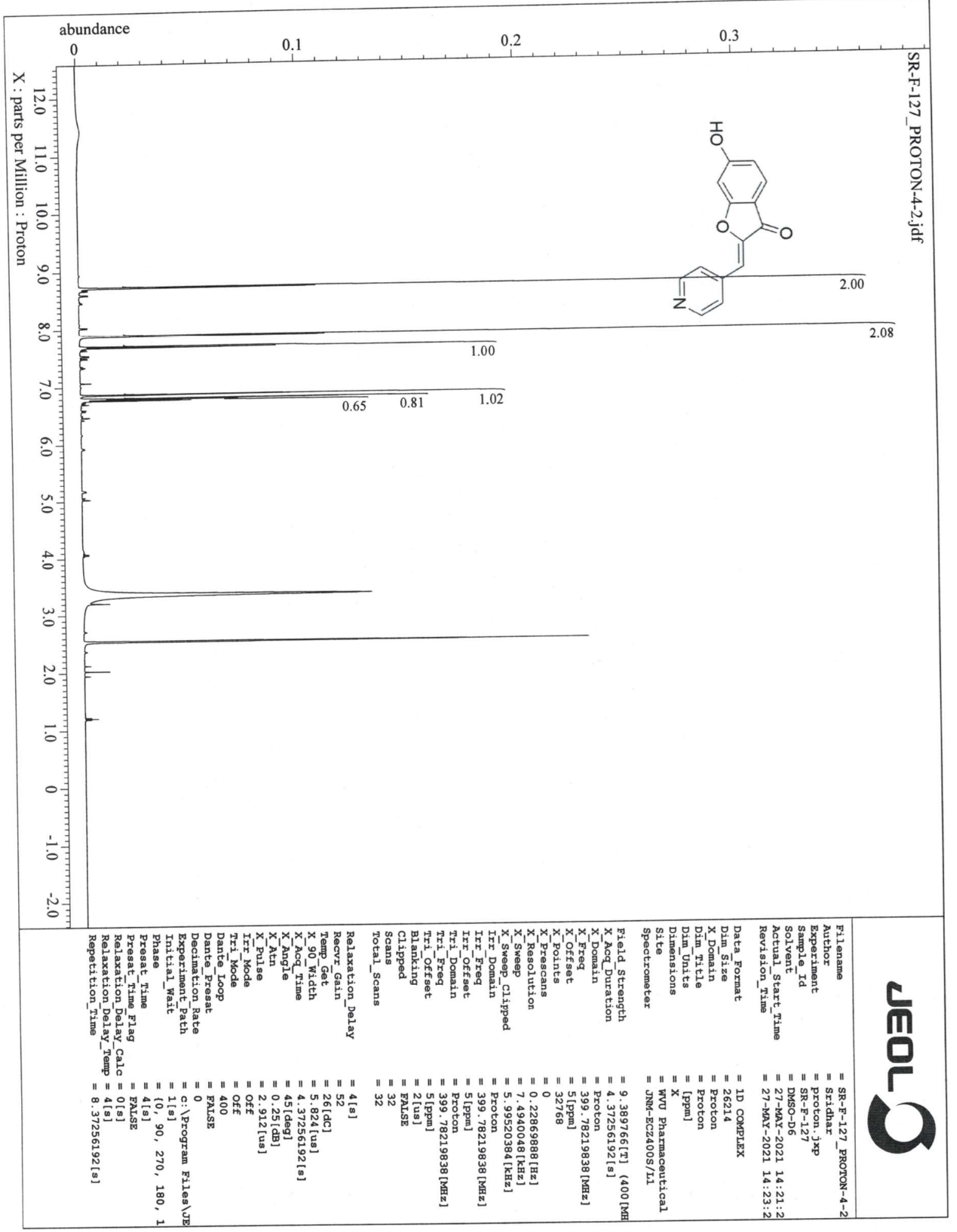




\section{${ }^{13}$ C NMR of SR-F-127}

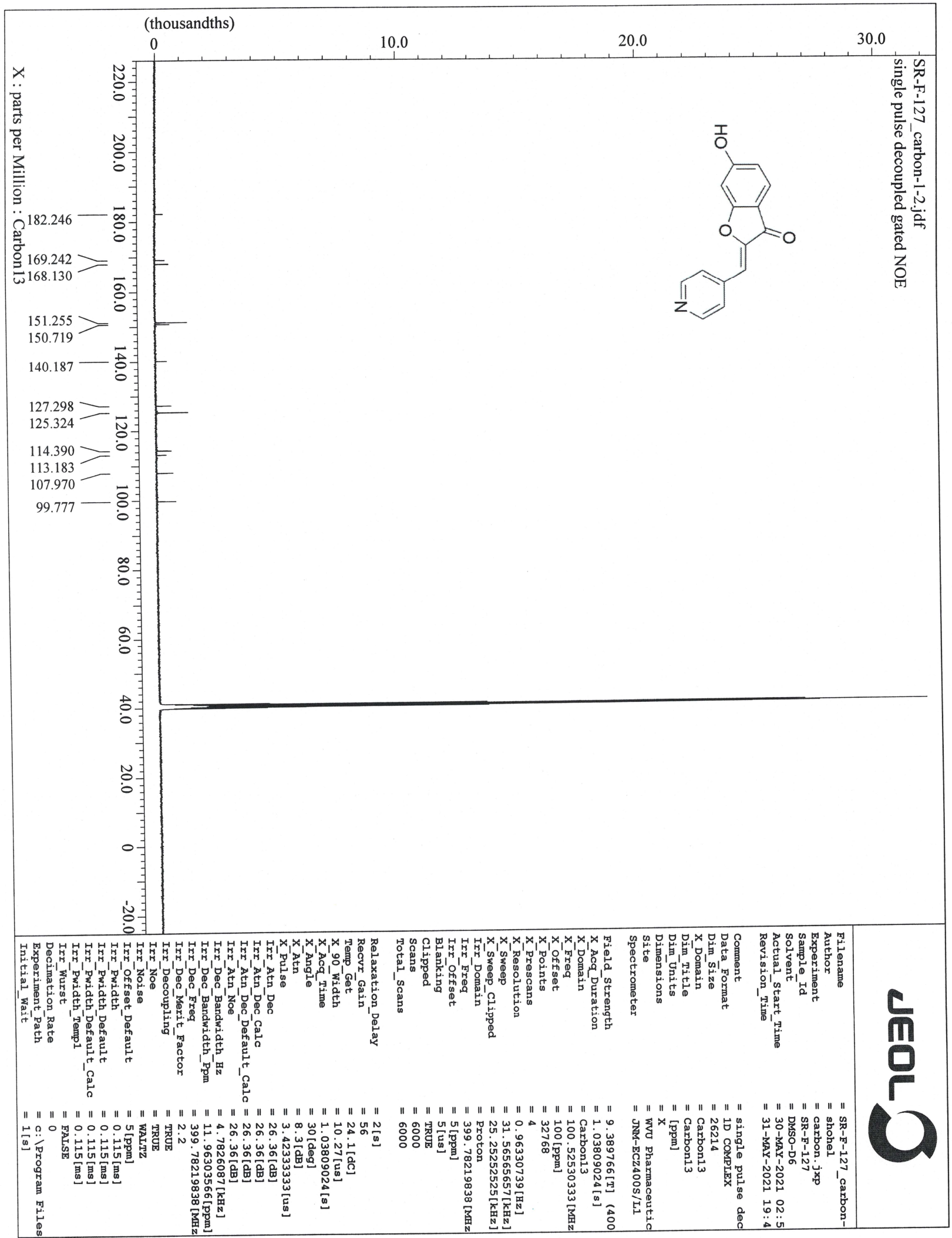


${ }^{13}$ C DEPT NMR of SR-F-127

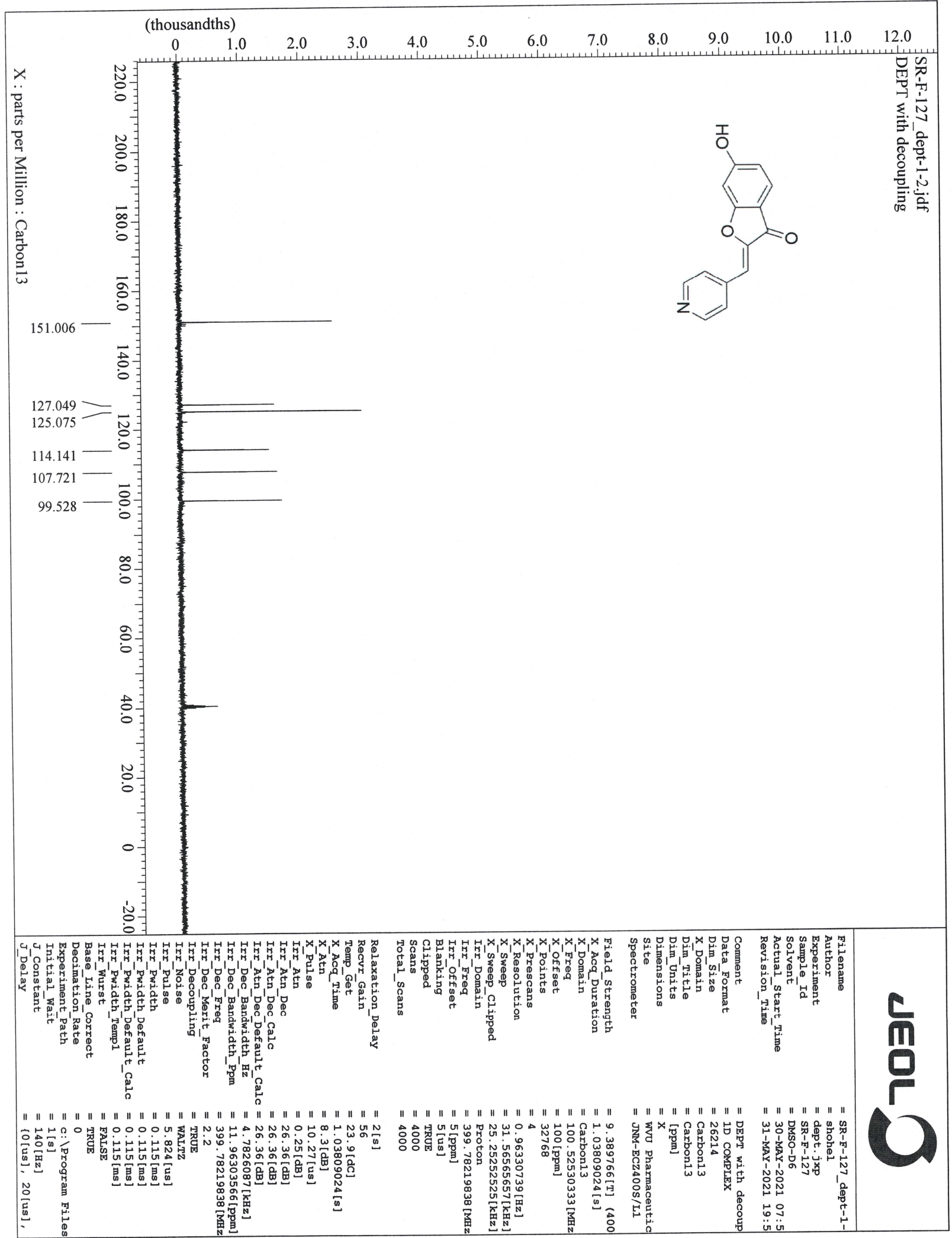




\section{Analytical HPLC Chromatogram of SR-F-127}

Data File C: \CHEM32\1\DATA \SRIDHAR\SRIDHAR-BOOK-F\SR-F-127-03192021.D

Sample Name: SR-F-127

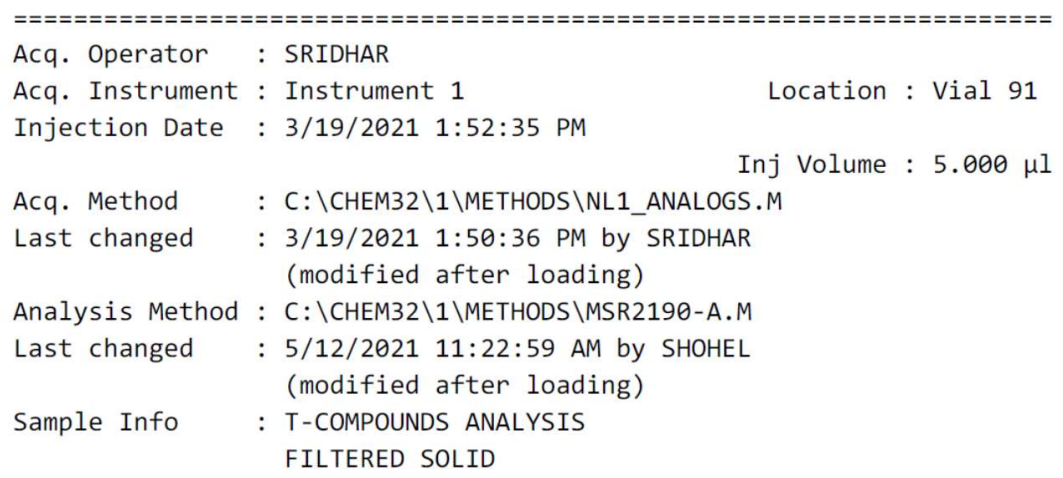

Additional Info : Peak(s) manually integrated

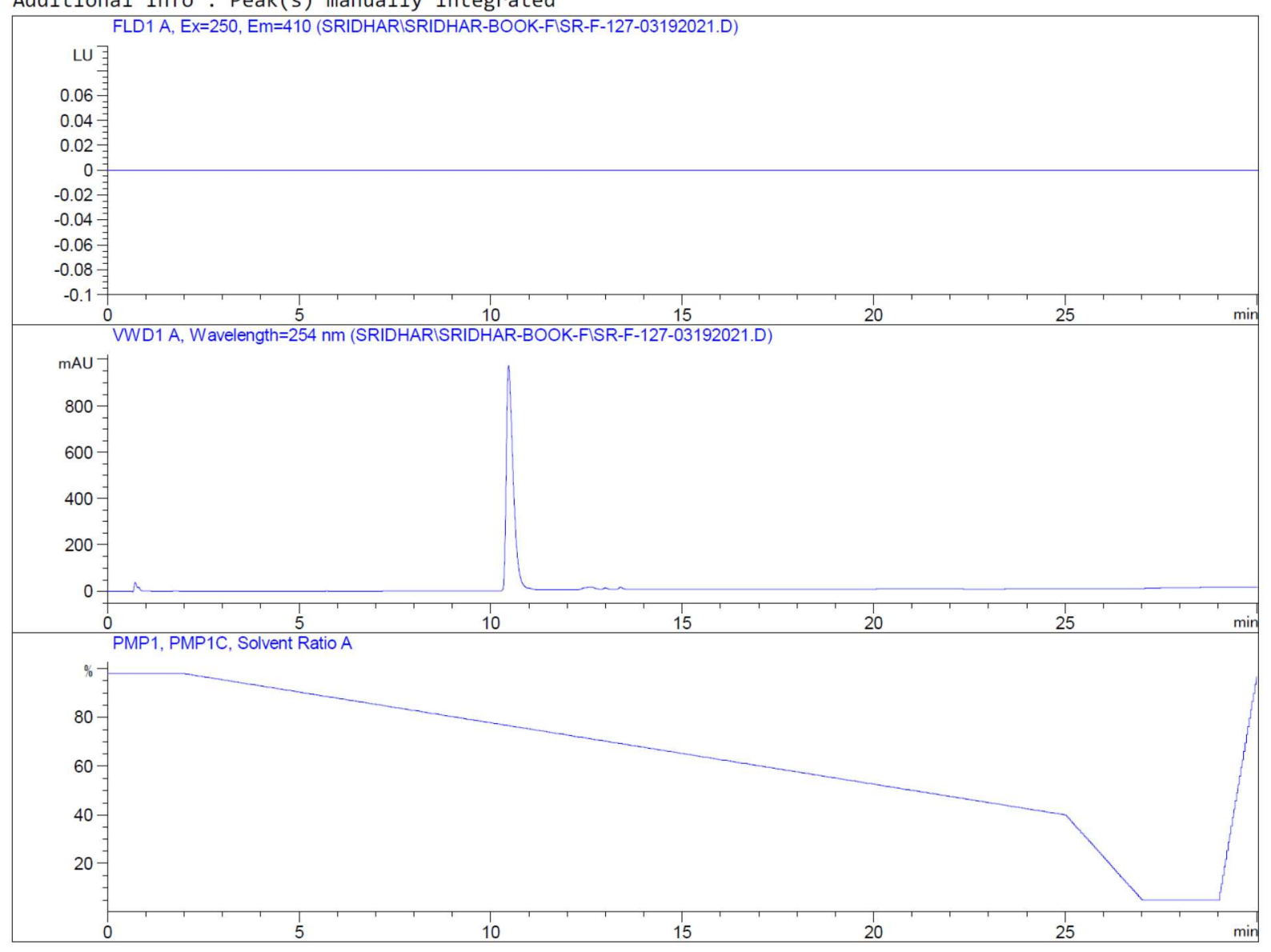




\section{${ }^{1} \mathrm{H}$ NMR of SR-F-128}

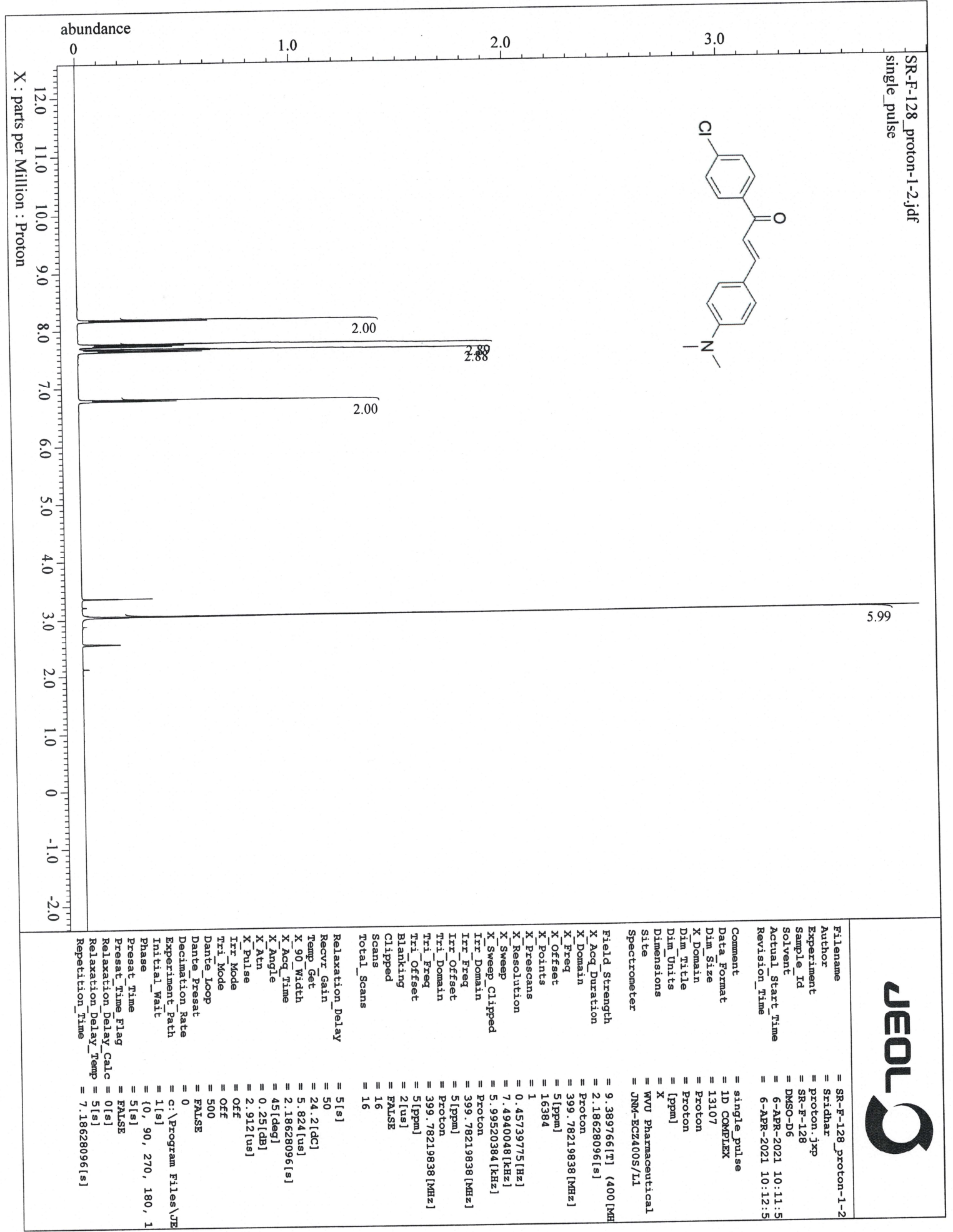




\section{${ }^{13}$ C NMR of SR-F-128}

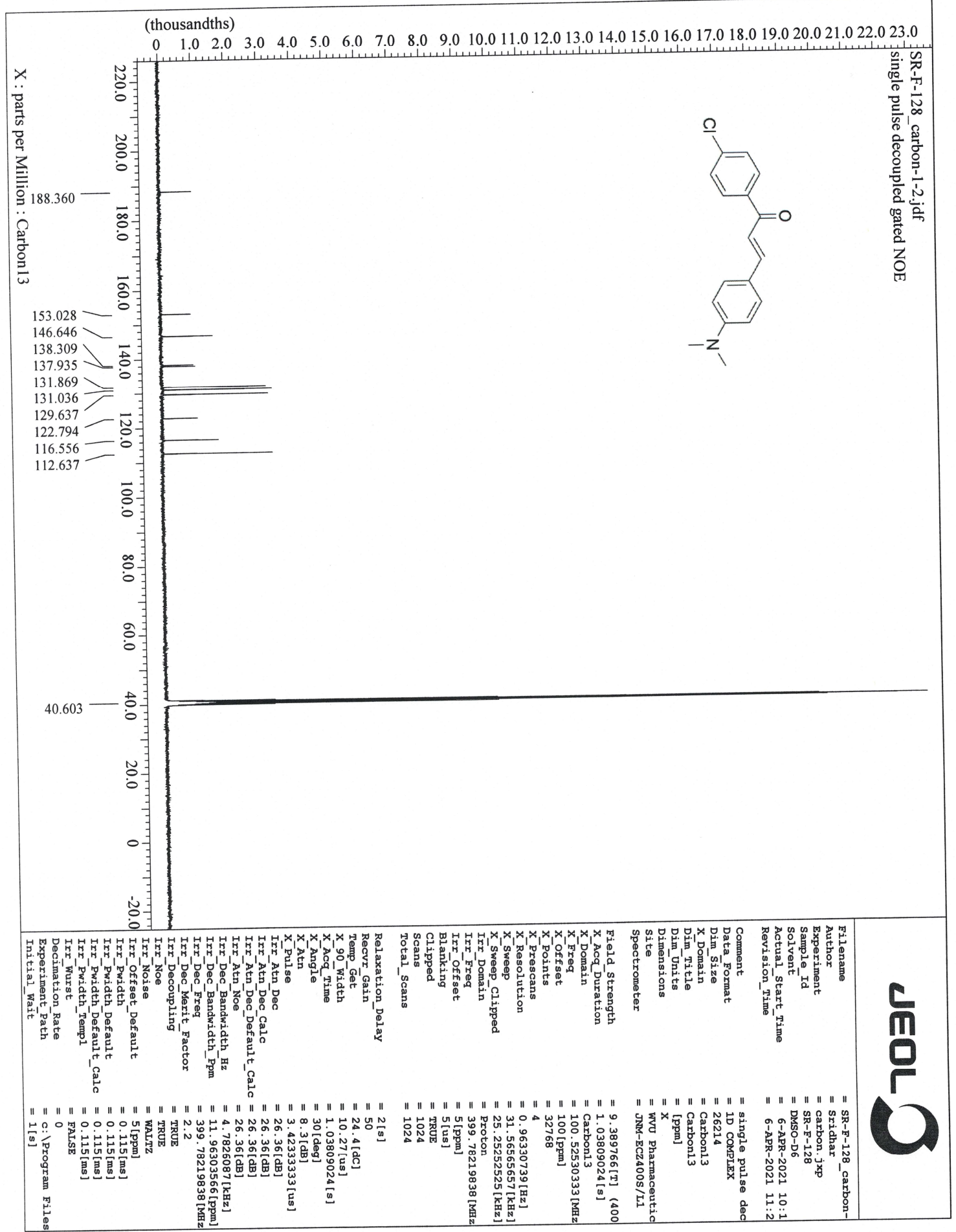




\section{${ }^{13}$ C DEPT NMR of SR-F-128}

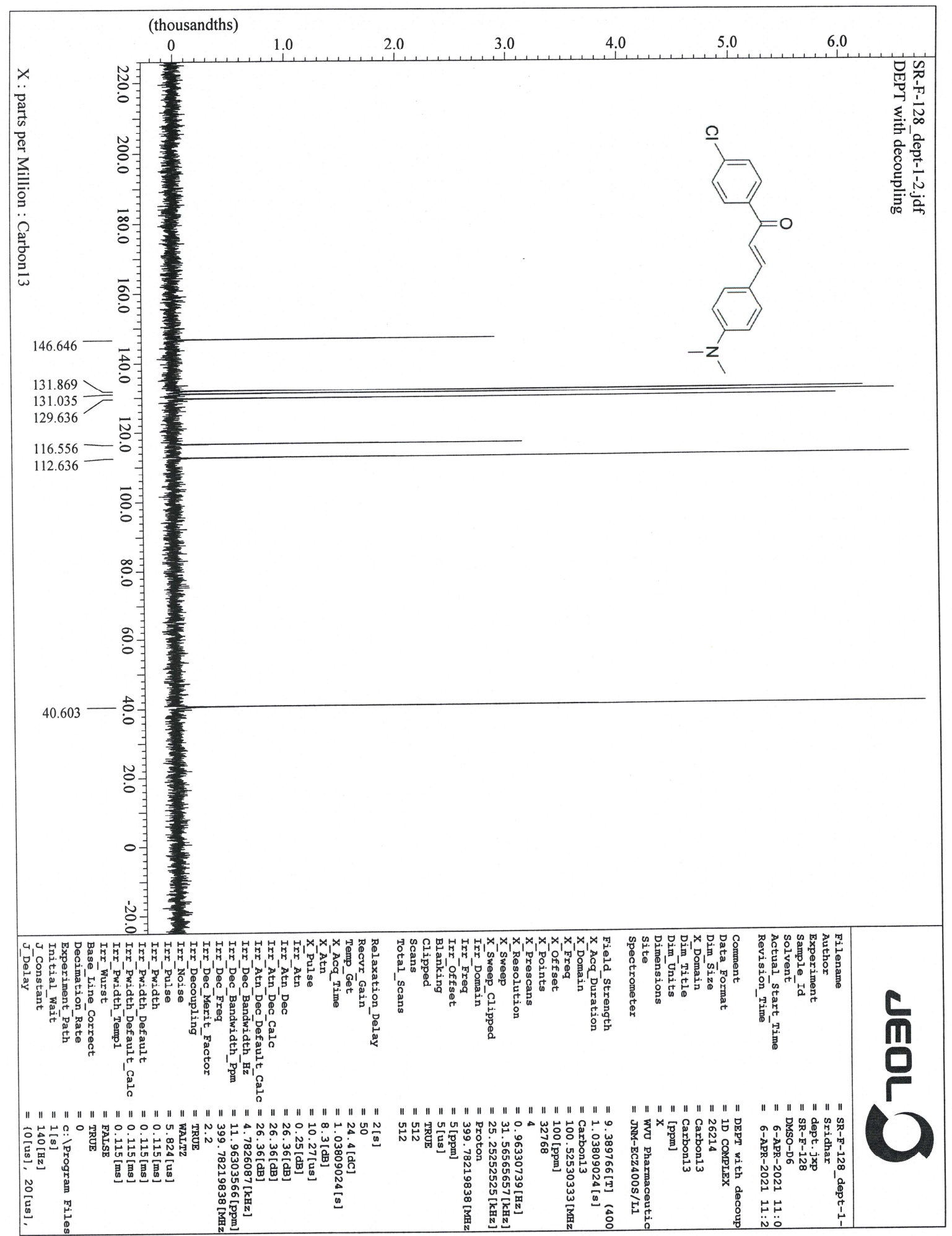




\section{Analytical HPLC Chromatogram of SR-F-128}

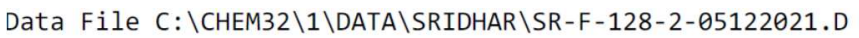

Sample Name: SR-F-128

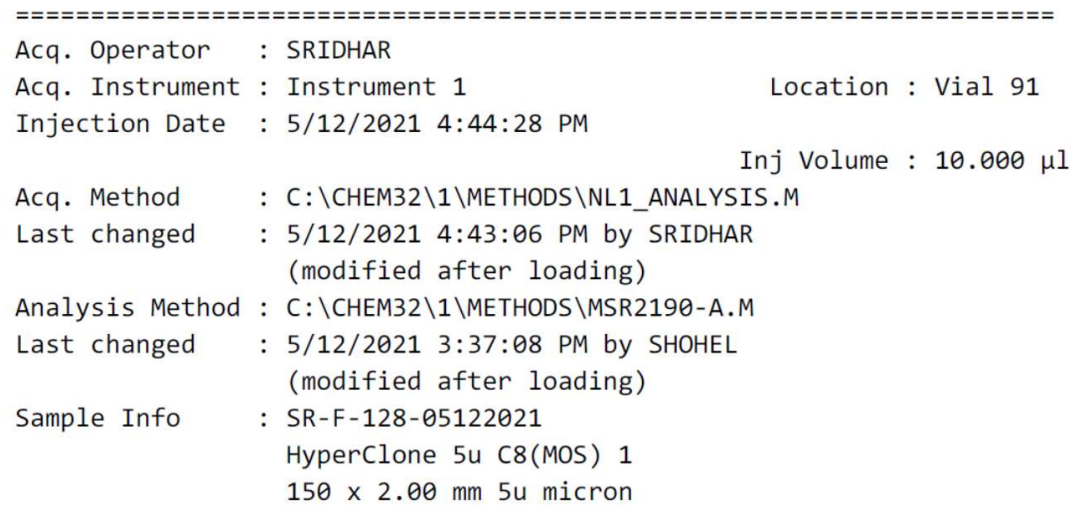

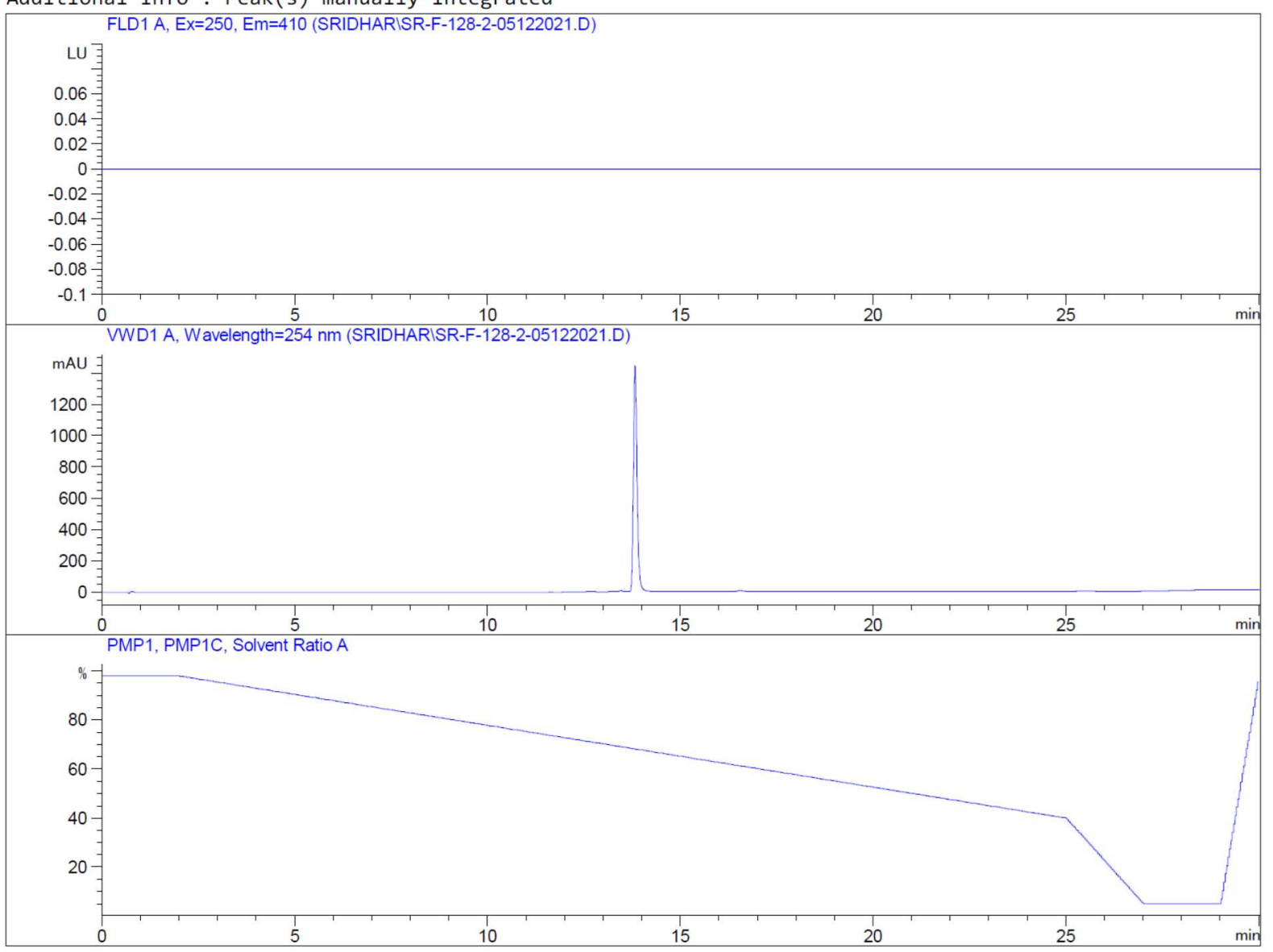




\section{${ }^{1}$ H NMR of SR-F-129}

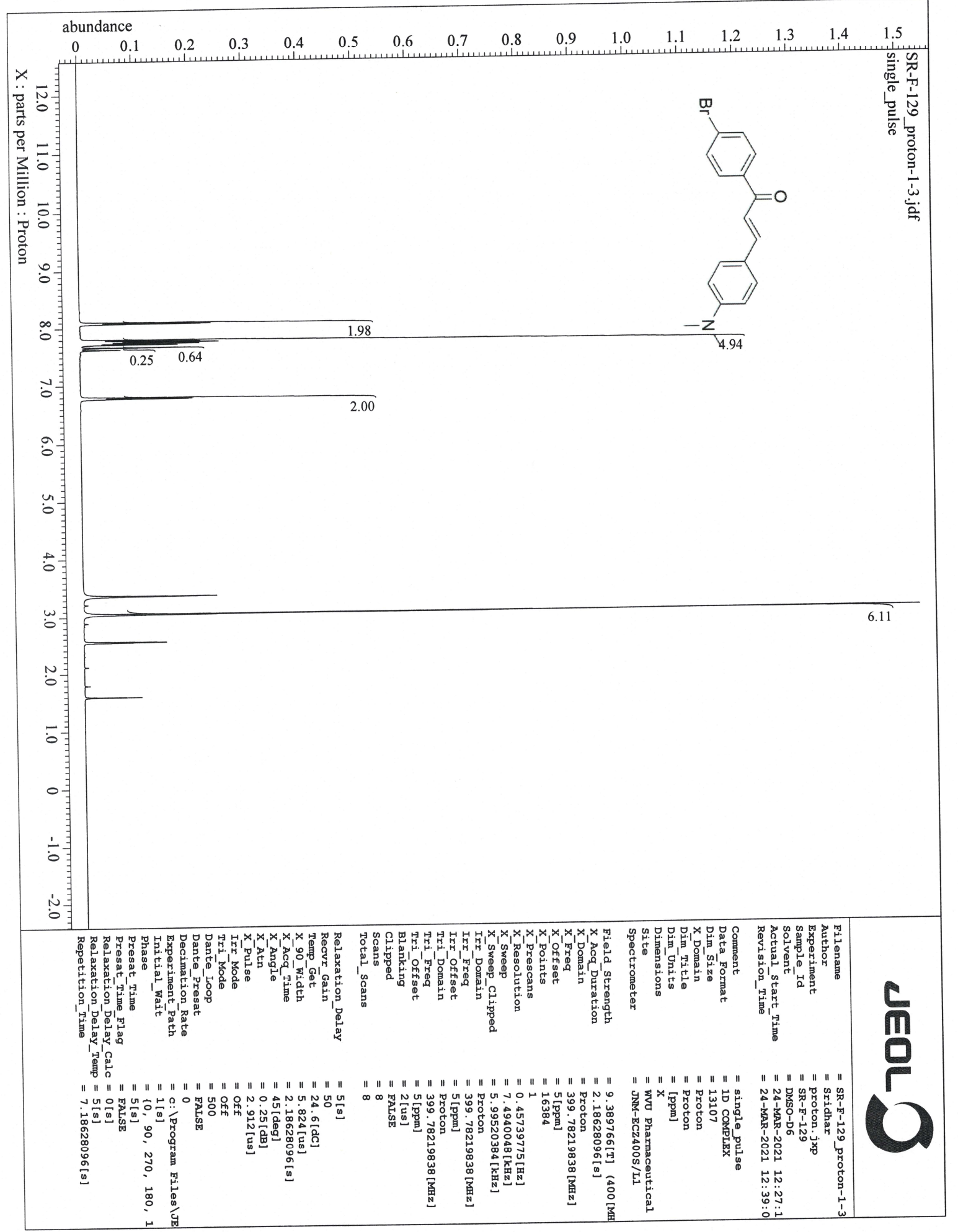




\section{${ }^{13}$ C NMR of SR-F-129}

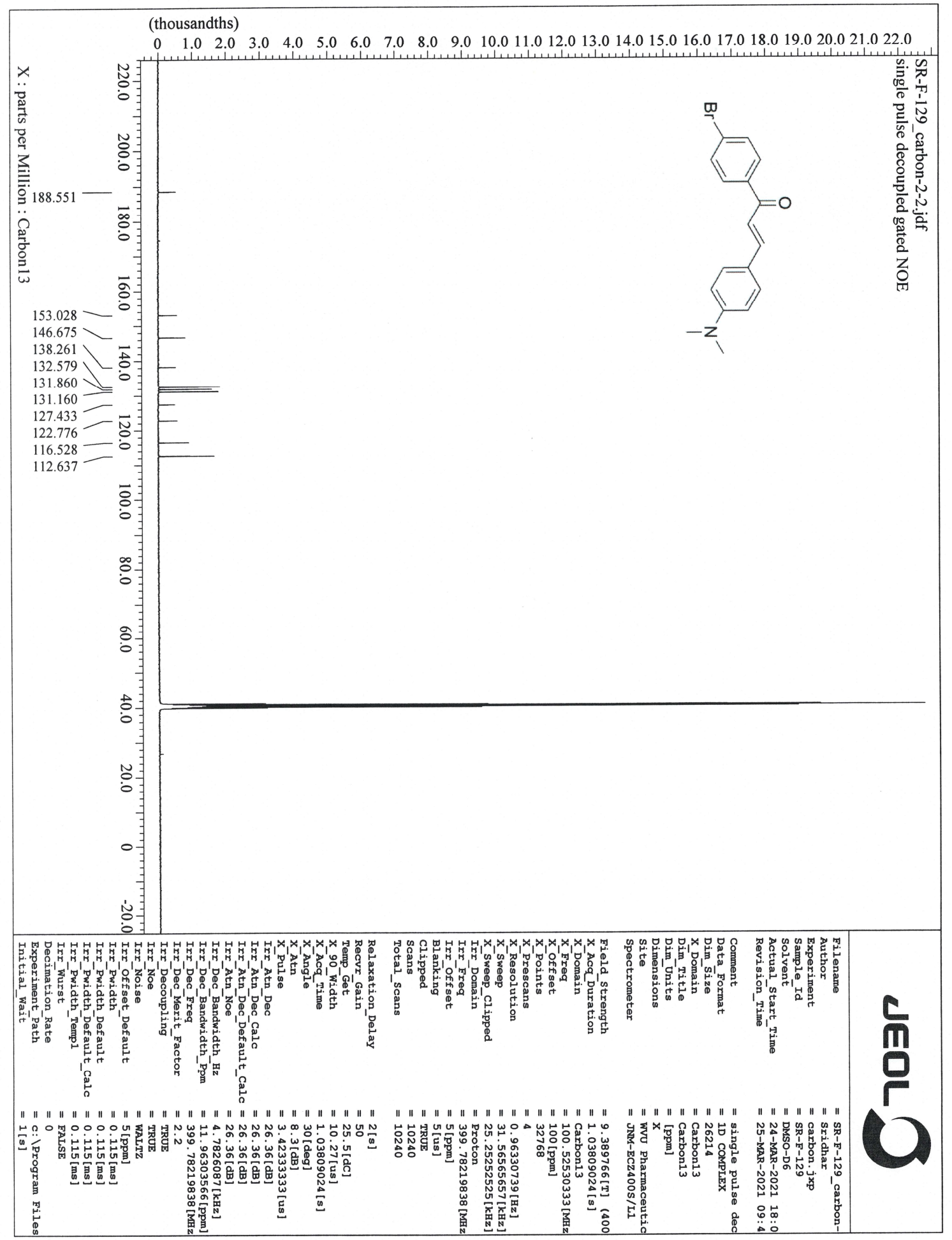




\section{${ }^{13}$ C DEPT NMR of SR-F-129}

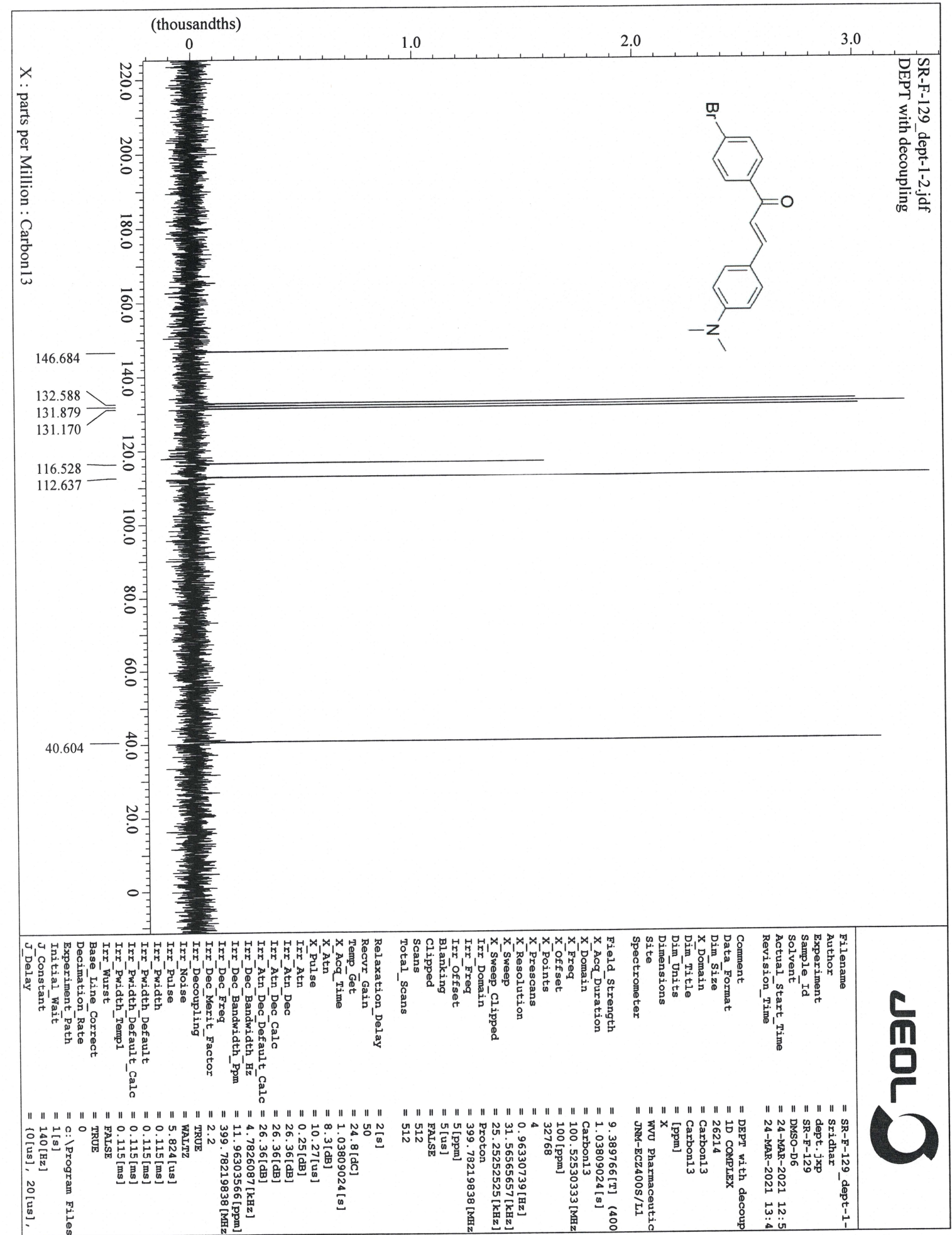




\section{Analytical HPLC Chromatogram of SR-F-129}

Data File C: \CHEM32\1\DATA \SRIDHAR\SRIDHAR-BOOK-F\SR-F-129-032321.D

Sample Name: SR-F-129
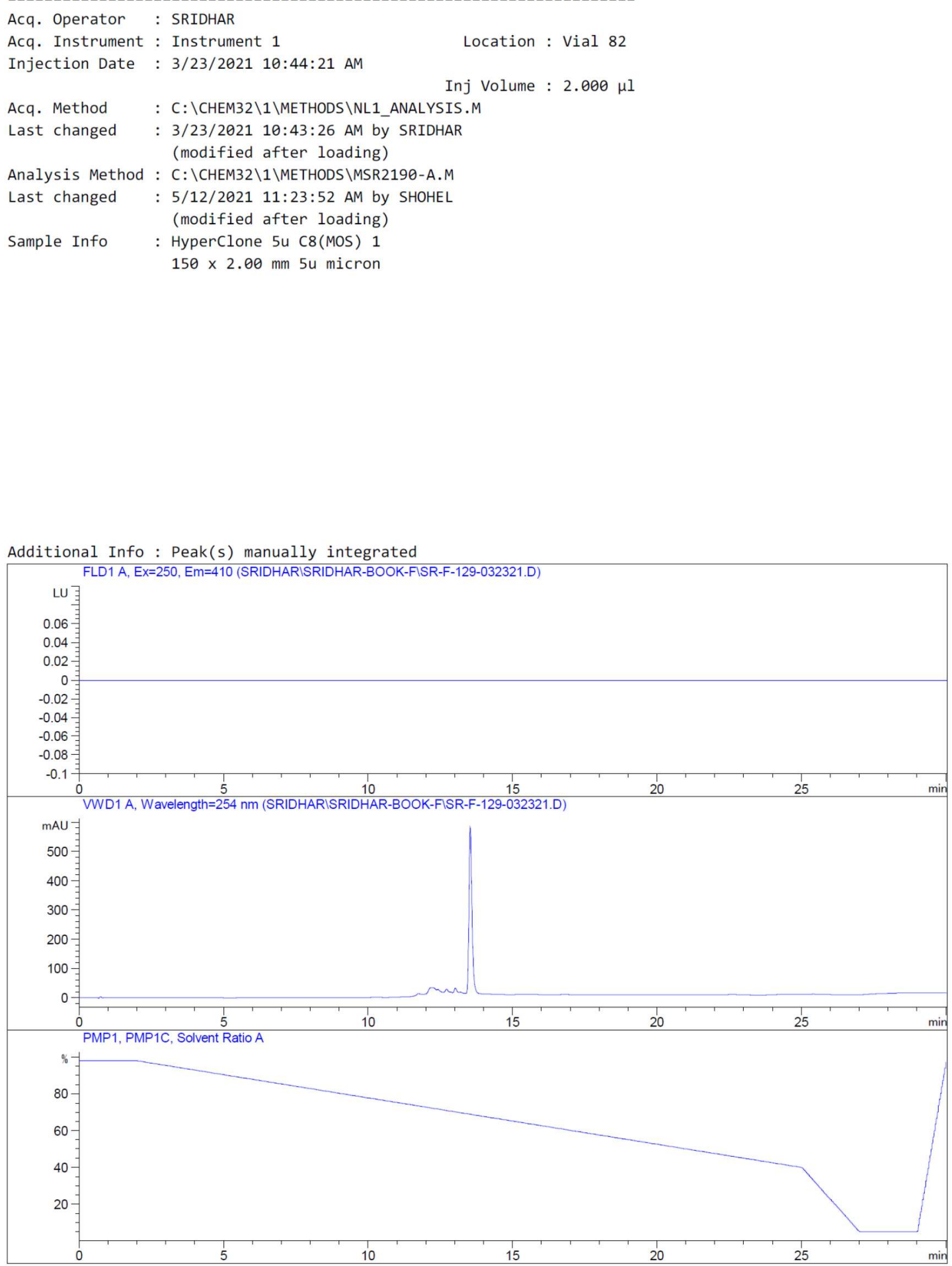


\section{${ }^{1} \mathrm{H}$ NMR of SR-F-130}

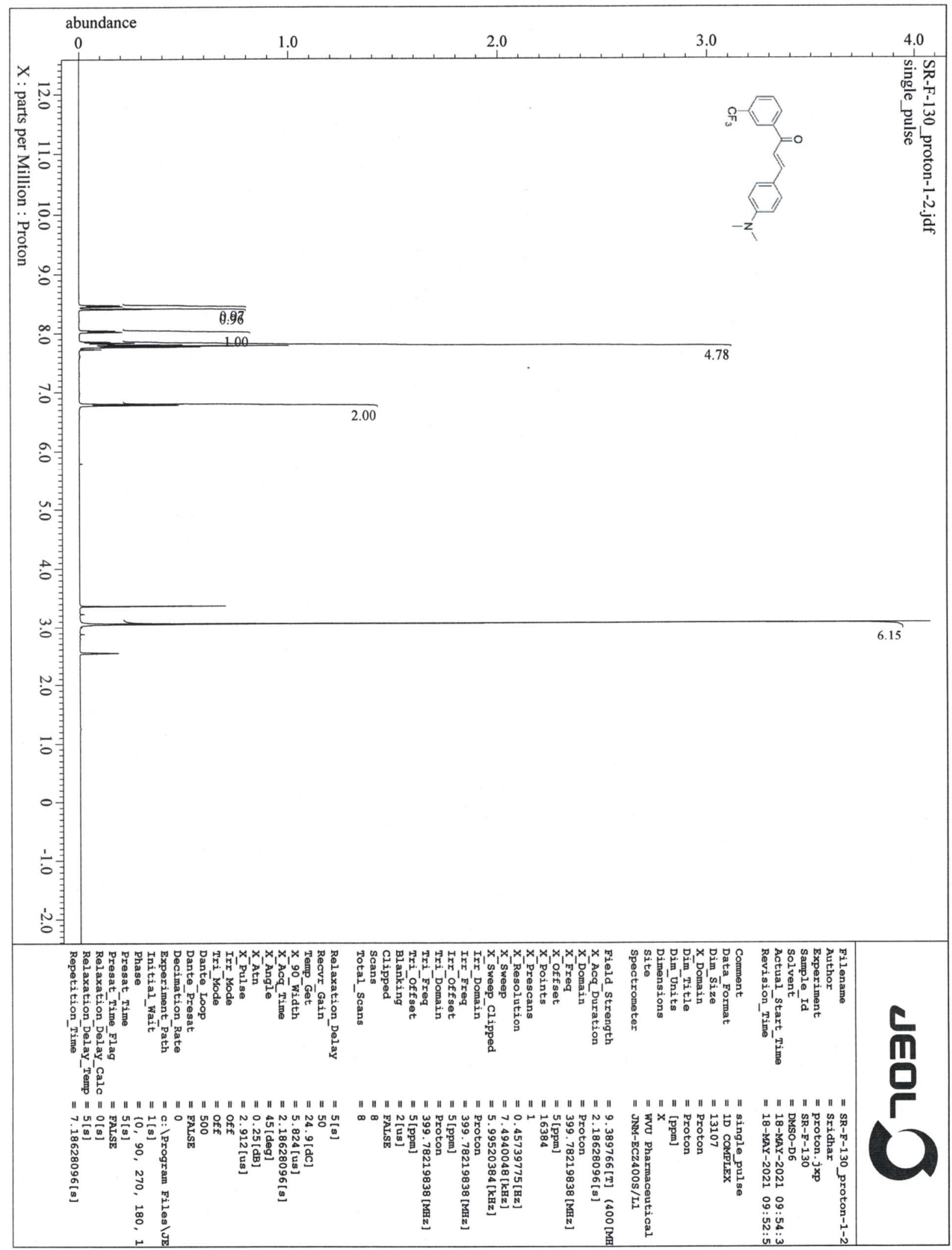




\section{${ }^{13}$ C NMR of SR-F-130}

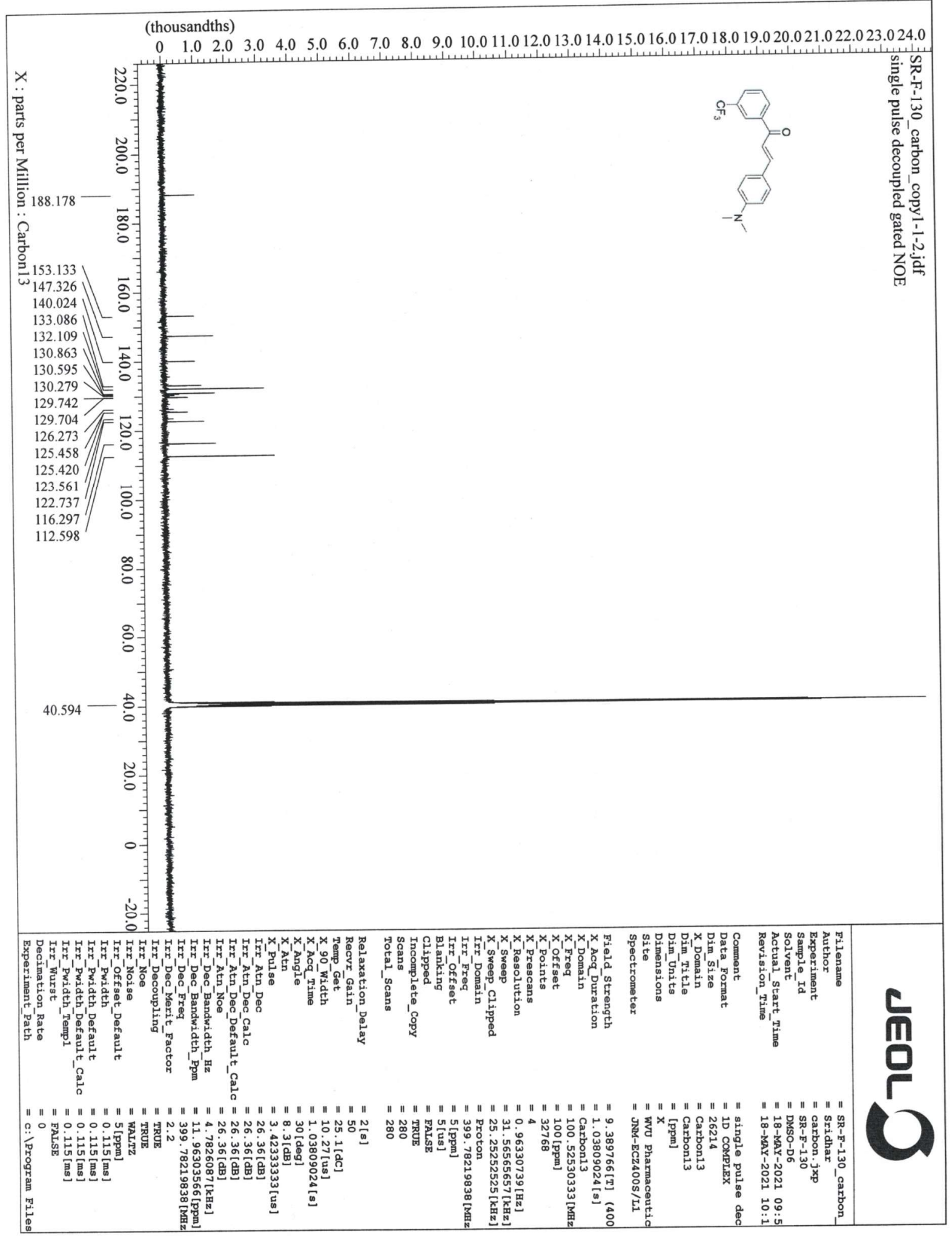




\section{${ }^{13}$ C DEPT NMR of SR-F-130}

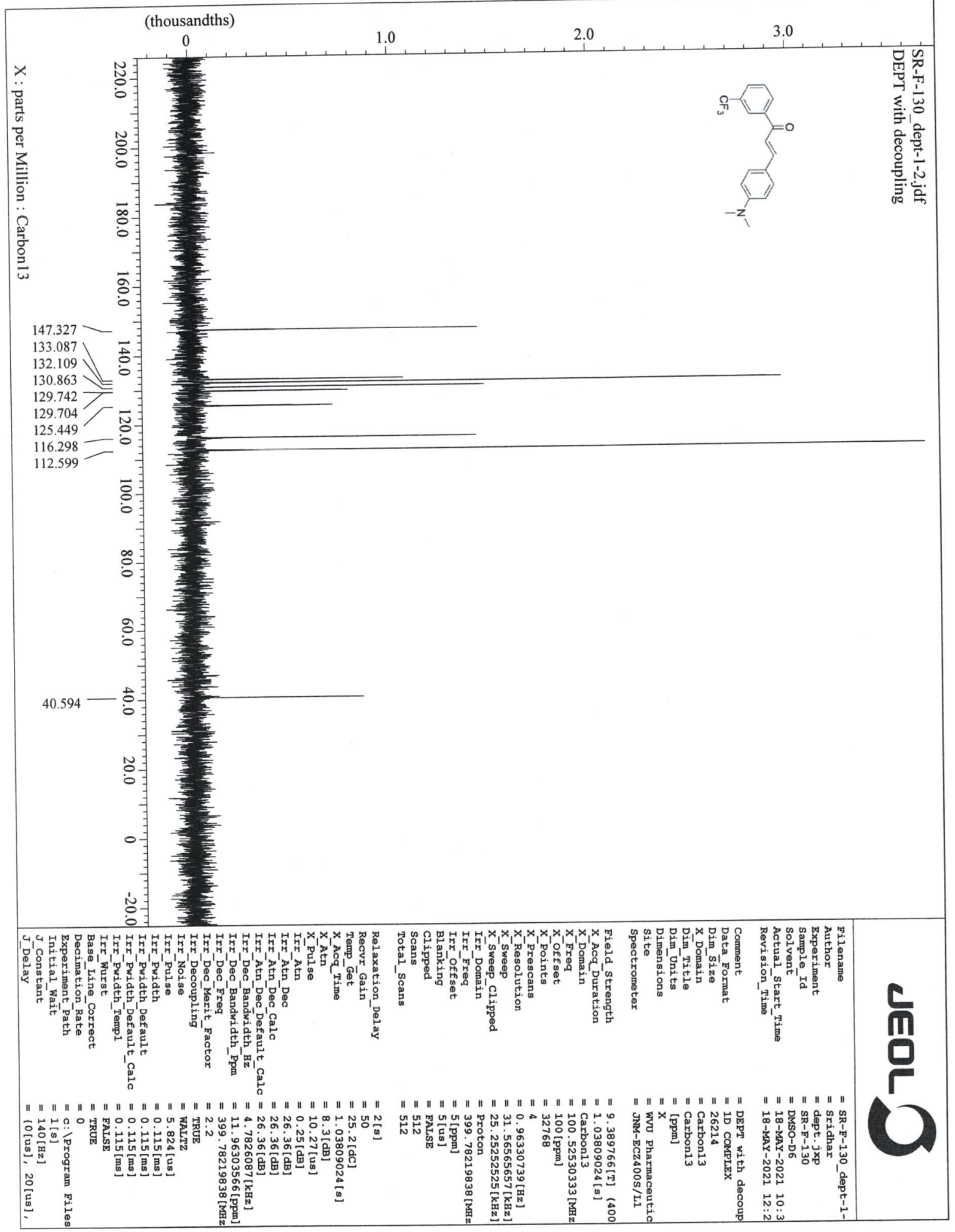


${ }^{19}$ F NMR of SR-F-130

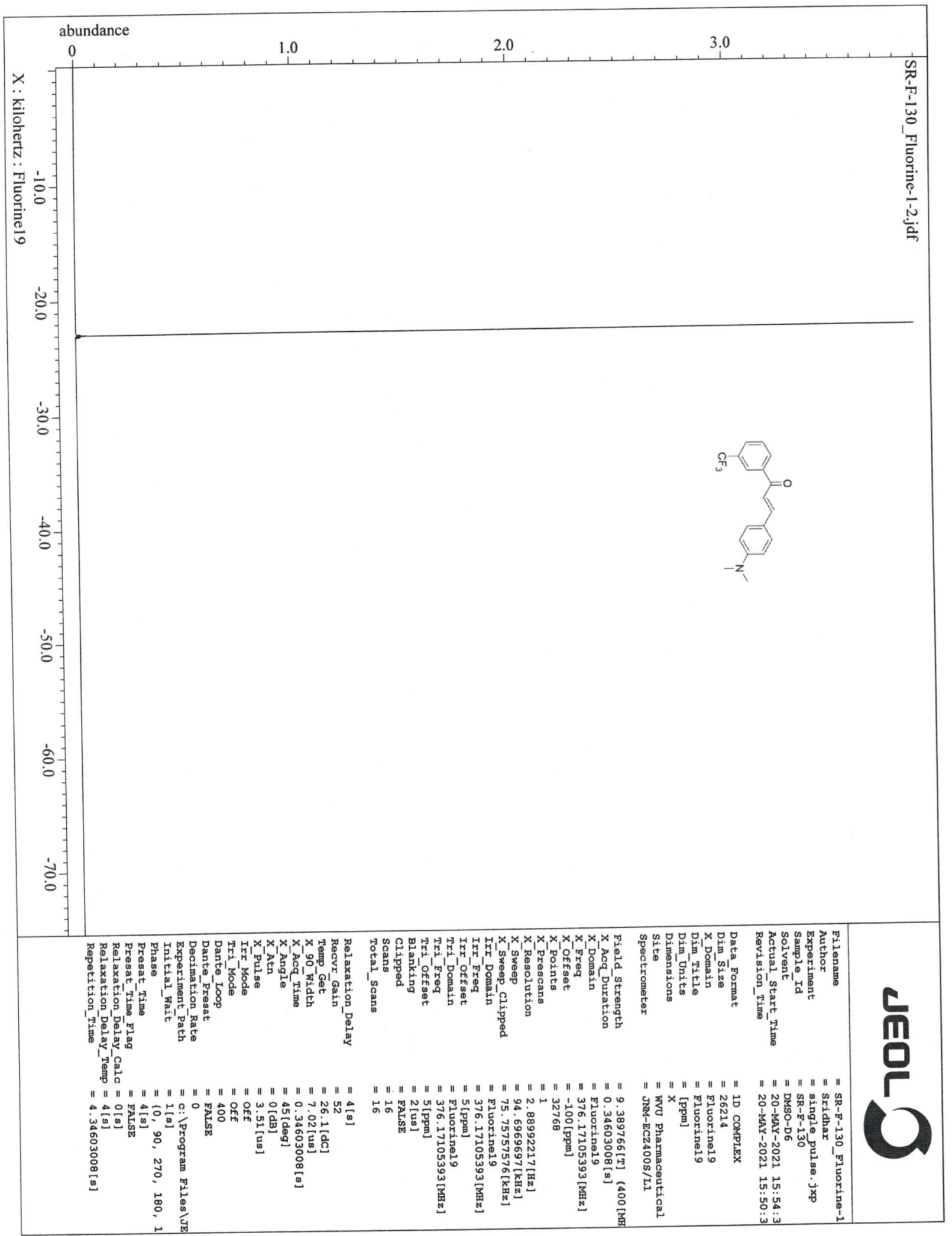




\section{Analytical HPLC Chromatogram of SR-F-130}

Data File C: \CHEM32\1\DATA \SRIDHAR \SRIDHAR-BOOK-F\SR-F-13--HPLC1-032321.D

Sample Name: SR-F-130
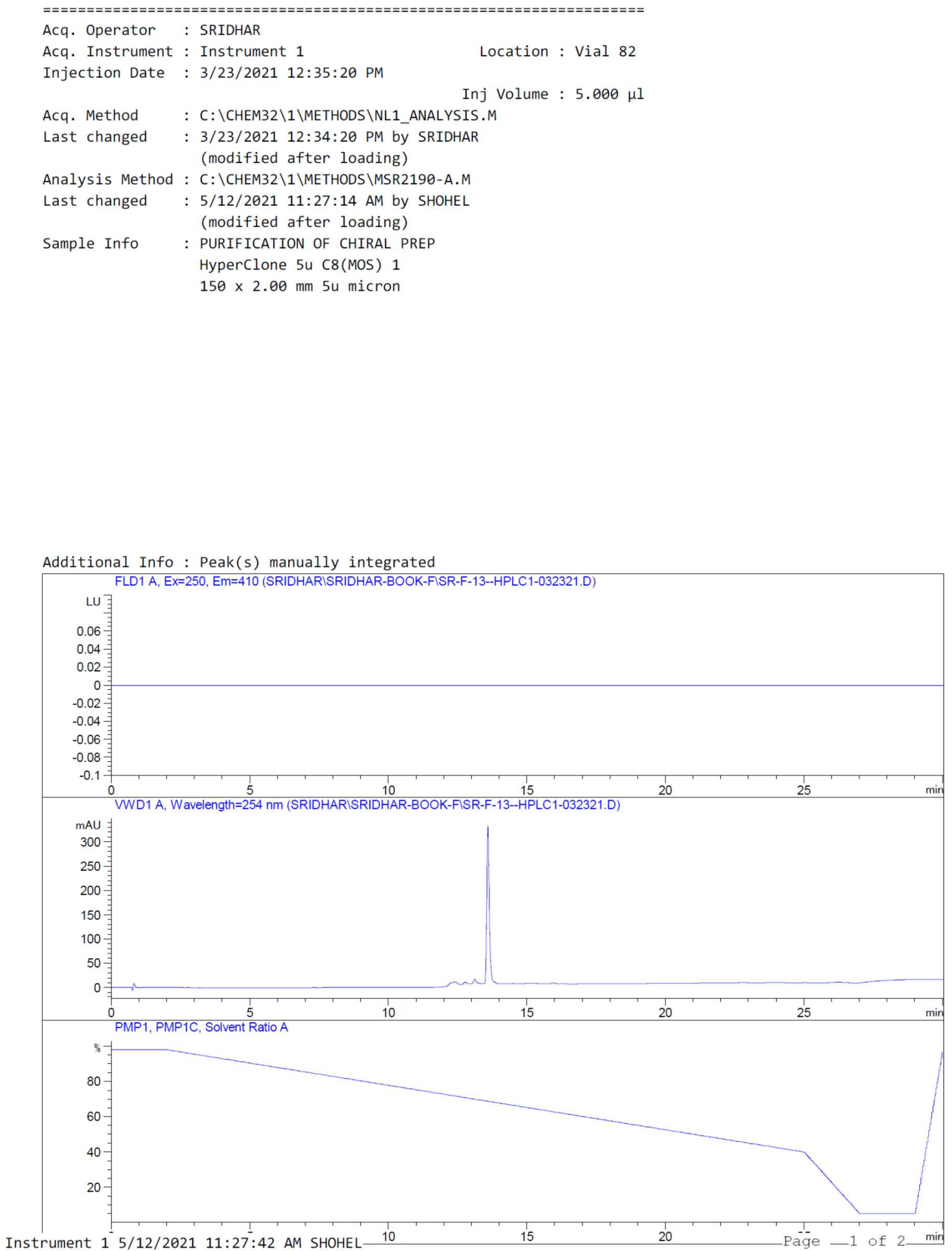


\section{${ }^{1}$ H NMR of SR-F-131}

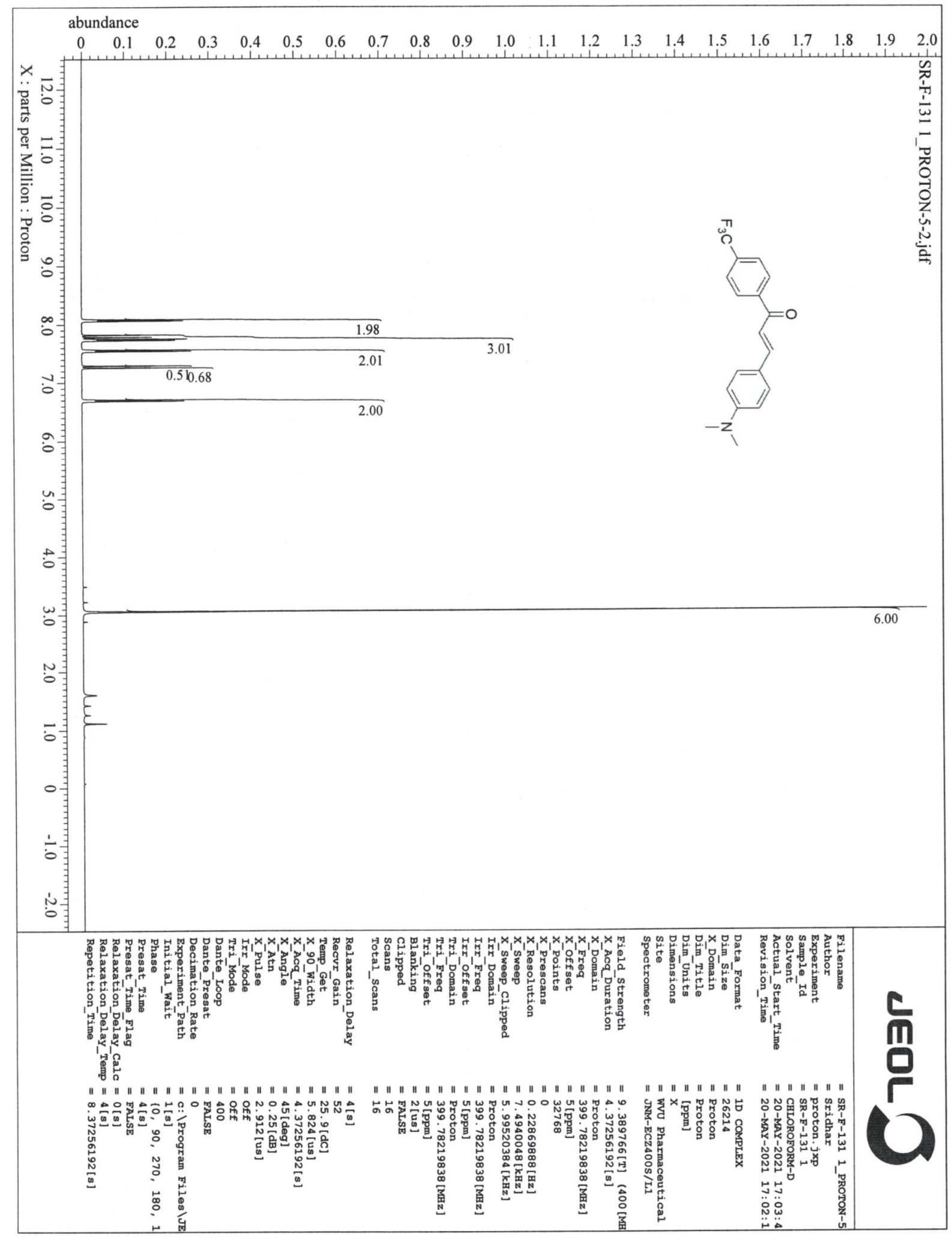




\section{${ }^{13}$ C NMR of SR-F-131}

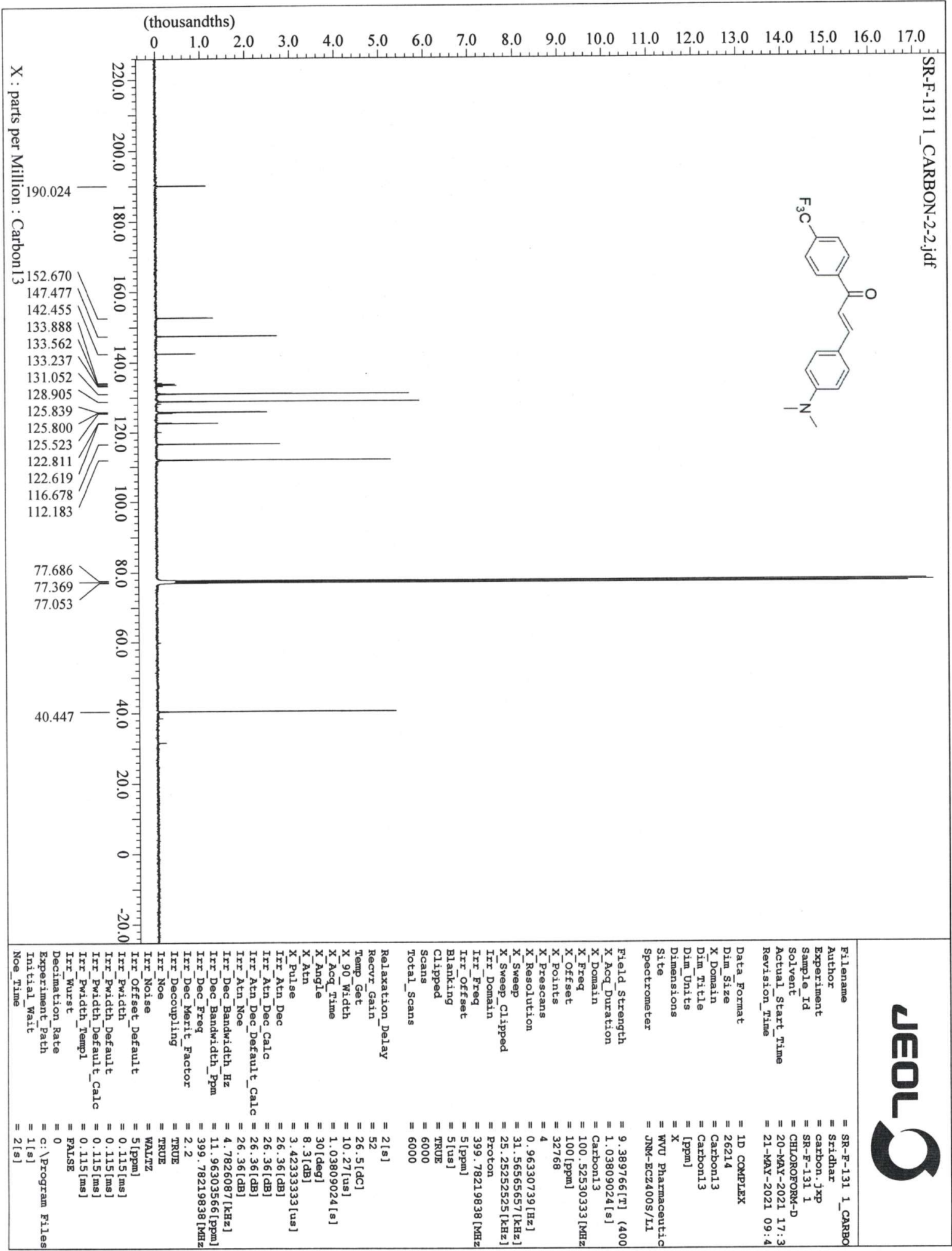


${ }^{13}$ C DEPT NMR of SR-F-131

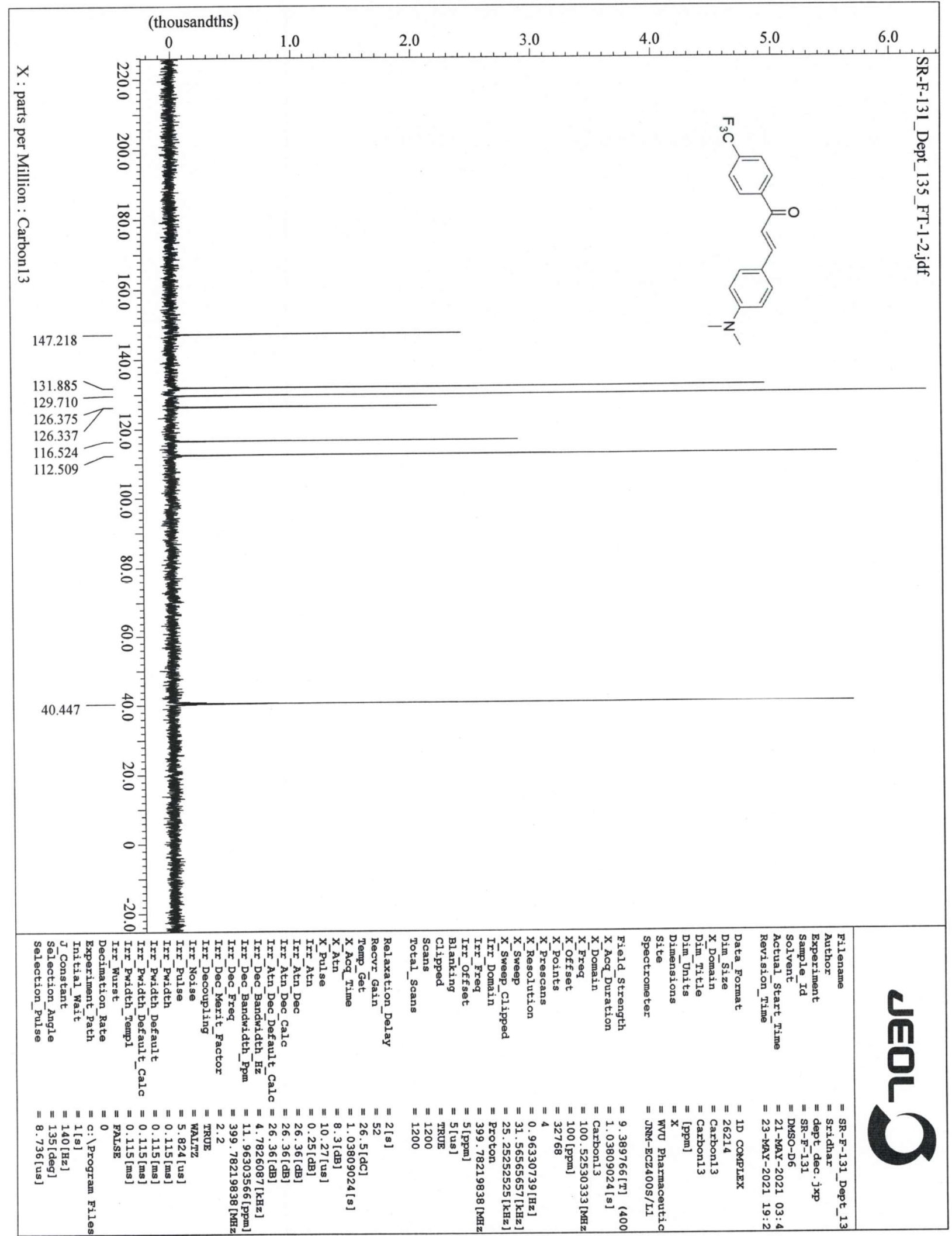


${ }^{19}$ F NMR of SR-F-131

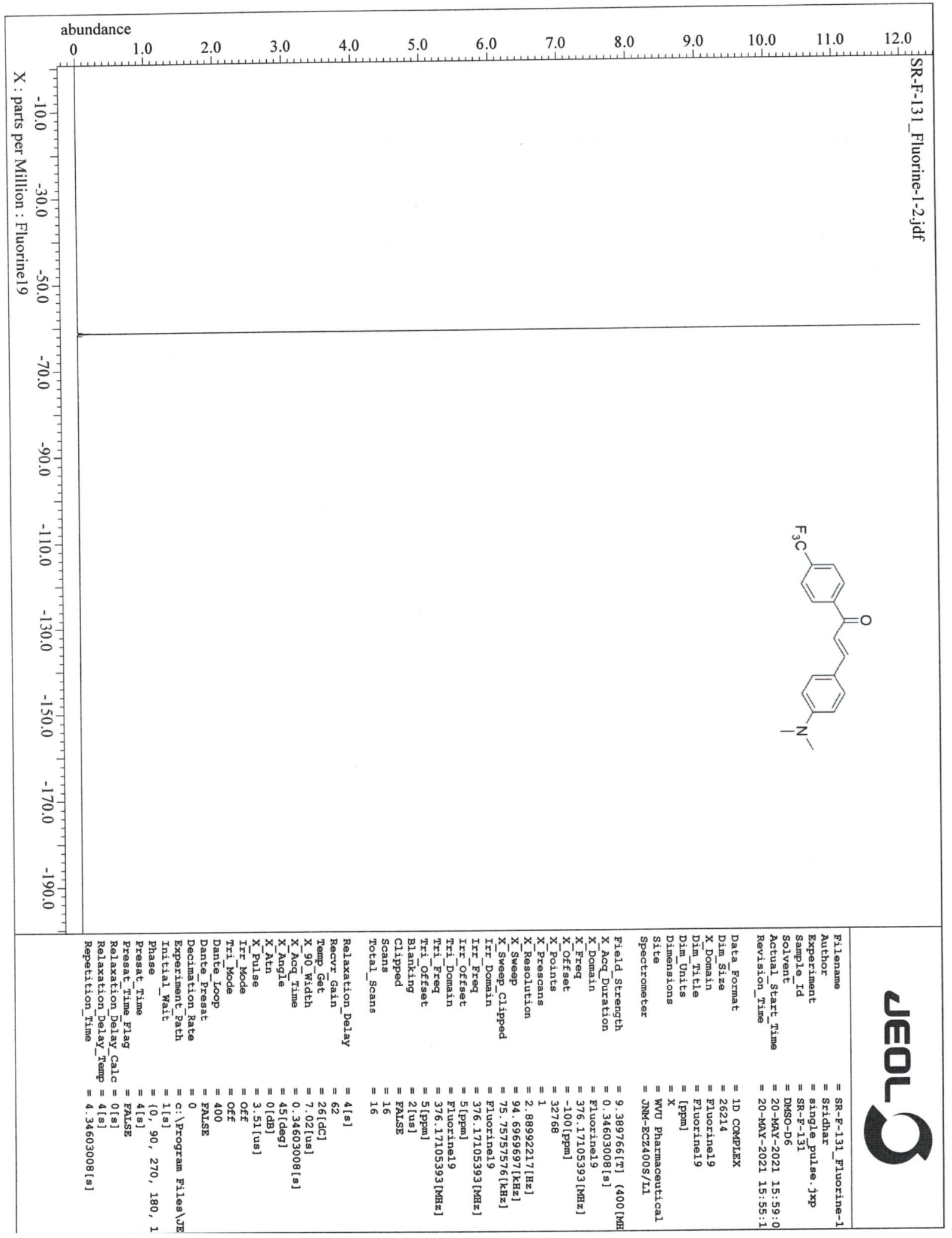




\section{Analytical HPLC Chromatogram of SR-F-131}

Data File C: \CHEM32\1\DATA \SRIDHAR\SR-F-131-FR5-1-03262021.D

Sample Name: SR-F-131

\begin{tabular}{|c|c|c|}
\hline Acq. Operator & : SRIDHAR & \\
\hline Acq. Instrument & : Instrument 1 & Location : Vial 82 \\
\hline Injection Date & : 3/26/2021 12:21:45 PM & \\
\hline
\end{tabular}

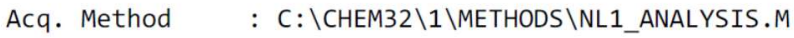

Last changed : 3/26/2021 12:20:27 PM by SRIDHAR

(modified after loading)

Analysis Method : C: \CHEM32\1\METHODS\MSR2190-A.M

Last changed : 5/12/2021 11:27:42 AM by SHOHEL

(modified after loading)

Sample Info: FRACTION 5 FROM FLASH COLUMN

HyperClone $5 \mathrm{u}$ C8(MOS) 1

$150 \times 2.00 \mathrm{~mm} 5 \mathrm{u}$ micron

Additional Info : Peak(s) manually integrated

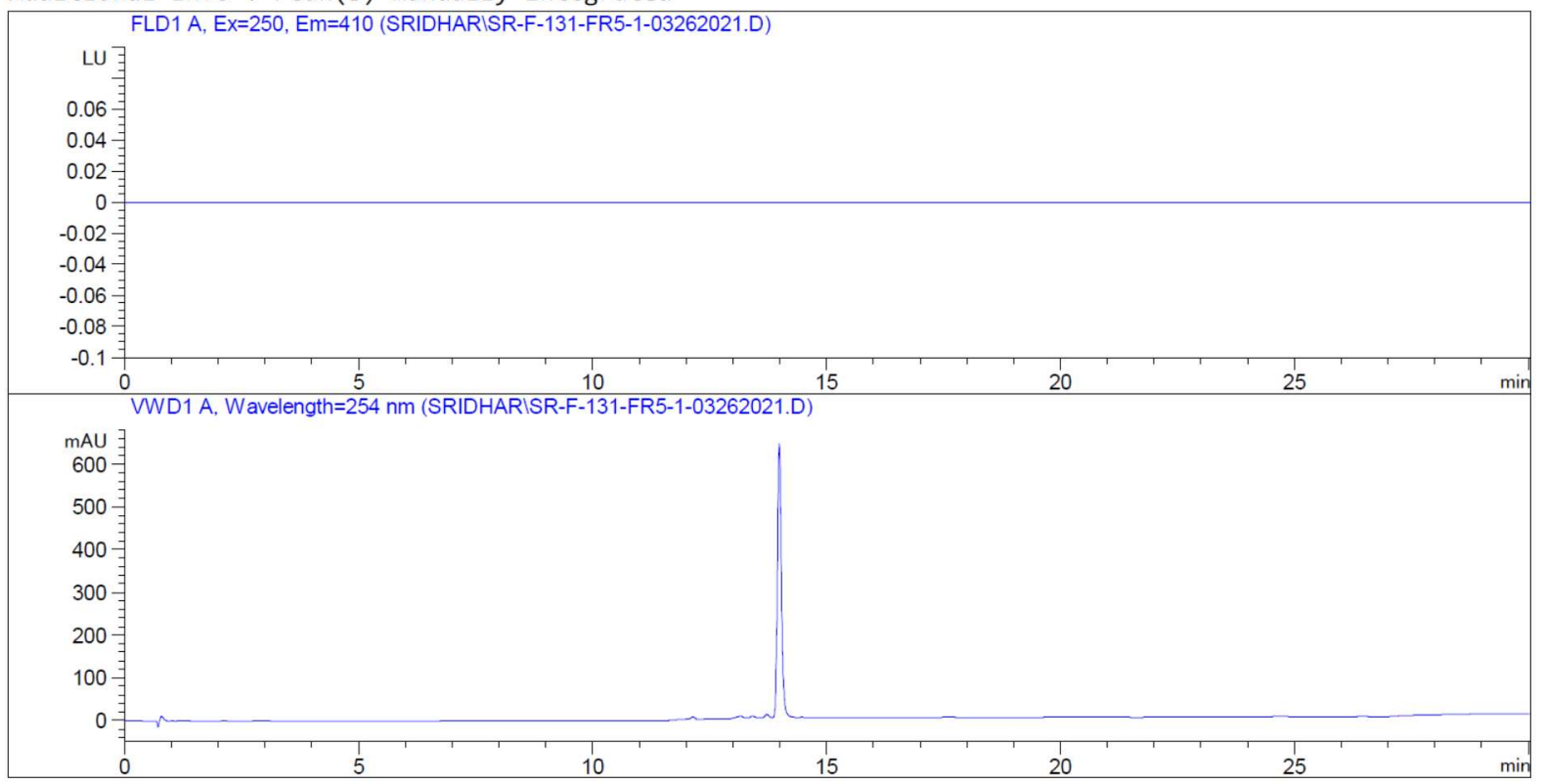




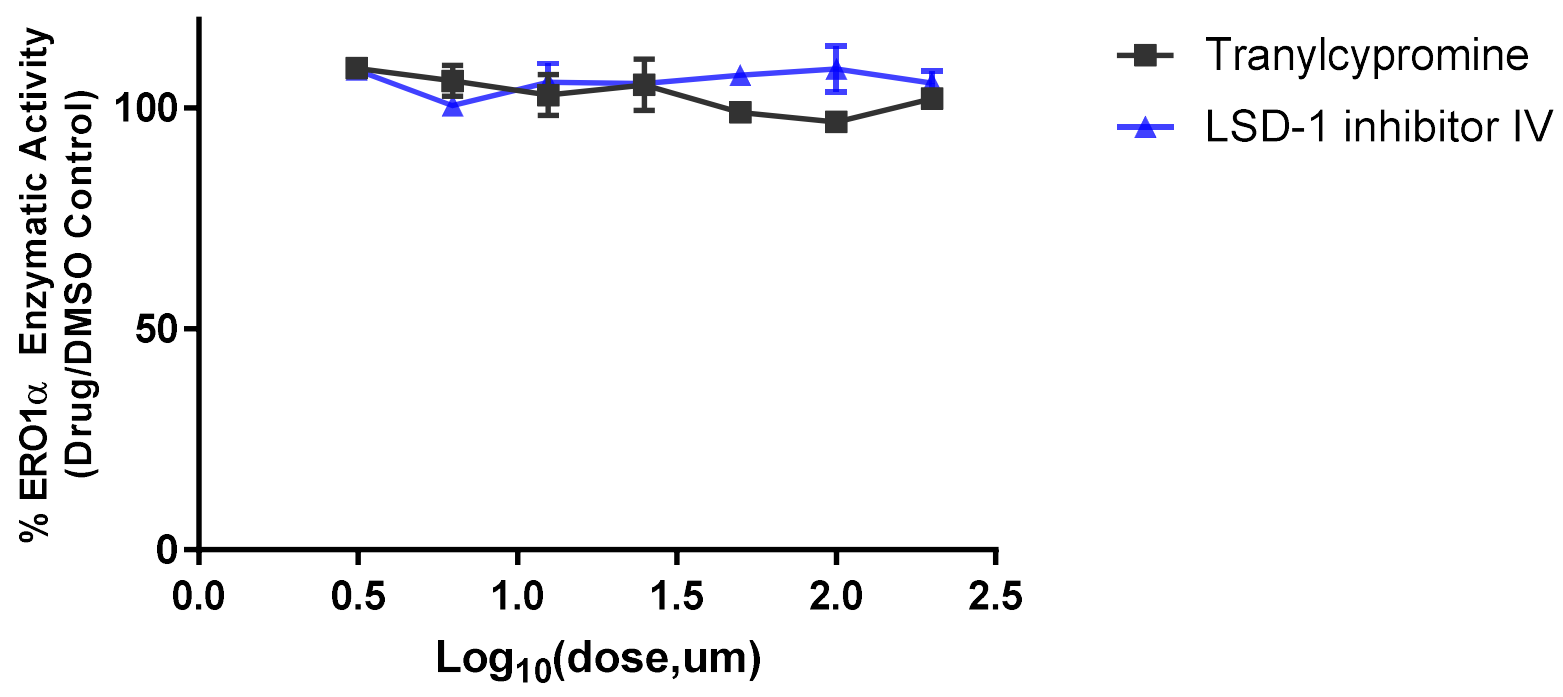

Supplemental Figure 1: FAD covalent modifiers tranylcypromine and LSD-1 inhibitor IV do not inhibit ERO1a. Tranylcypromine and LSD-1 inhibitor IV were used to generate a concentration response and as shown, no inhibition of ERO1 $\alpha$ was seen up to $200 \mu \mathrm{M}$. Experiments performed in triplicates and shown is the mean and standard deviation of three independent experiments. 


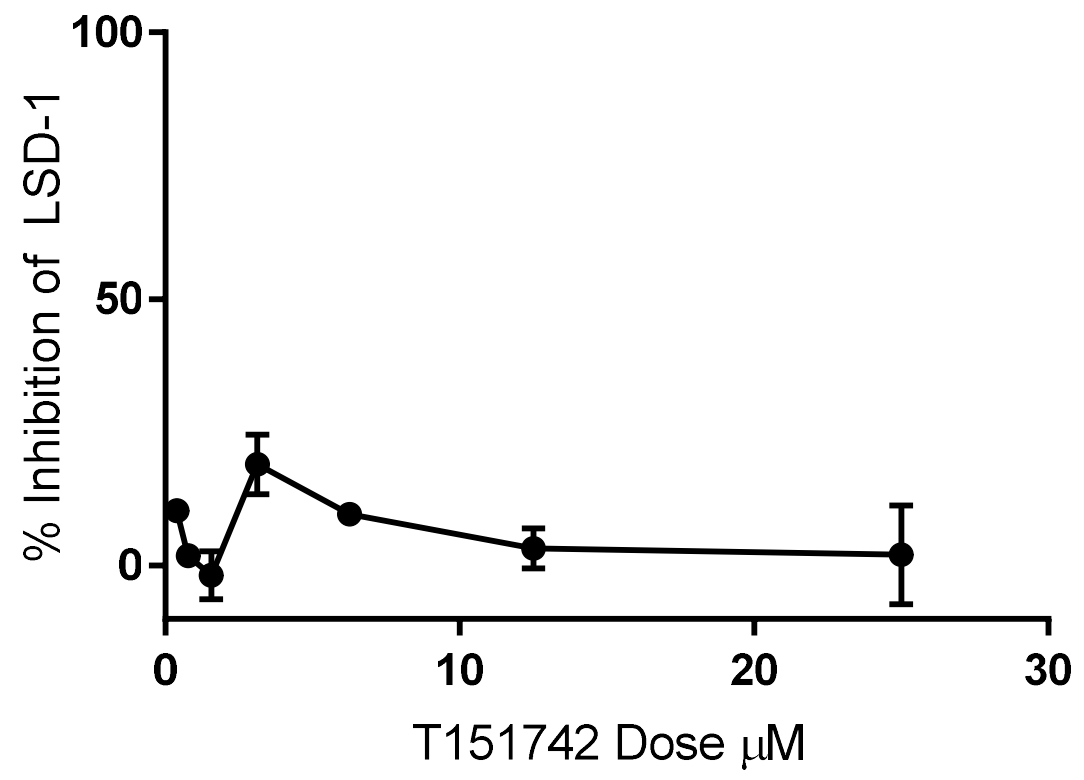

Supplemental Figure 2: T151742 does not inhibit LSD-1 in a recombinant system using the LSD-1 assay kit from Cayman Chemicals. Using T151742 was used to generate a concentration response. As shown, T151742 did not target LSD-1 recombinantly at concentrations $\leq 25 \mu \mathrm{M}$. Experiments performed in triplicates and shown is the mean and standard deviation of three independent experiments. 
Supplemental Table 1: Cell lines, Cell type, and IC50's calculated using the MTT. Experiments were performed in quadruplicates and shown is he mean and standard deviation of three independent experiments.

\begin{tabular}{|l|l|l|}
\hline Cell Line & $\mathrm{IC}_{50}$ Avg \pm s.d. $(\mathrm{n}=3)$ & Cell type \\
\hline PC-9 & $14.05 \pm 3.99 \mu \mathrm{M}$ & NSCLC (adenocarcinoma) \\
\hline HCC4006 & $18.51 \pm 4.66 \mu \mathrm{M}$ & NSCLC (adenocarcinoma) \\
\hline U266 & $8.93 \pm 1.13 \mu \mathrm{M}$ & Multiple Myeloma \\
\hline MM1.s & $7.45 \pm 1.12 \mu \mathrm{M}$ & Multiple Myeoloma \\
\hline Beas-2B & $>100 \mu \mathrm{M}$ & Normal Lung Epithelium \\
\hline
\end{tabular}

